\title{
Tracers of the extraterrestrial component in sediments and inferences for Earth's accretion history
}

\author{
Frank T. Kyte* \\ Center for Astrobiology, Institute of Geophysics and Planetary Physics, University of California, \\ Los Angeles, California 90095-1567, USA
}

\begin{abstract}
The study of extraterrestrial matter in sediments began with the discovery of cosmic spherules during the HMS Challenger Expedition (1873-1876), but has evolved into a multidisciplinary study of the chemical, physical, and isotopic study of sediments. Extraterrestrial matter in sediments comes mainly from dust and large impactors from the asteroid belt and comets. What we know of the nature of these source materials comes from the study of stratospheric dust particles, cosmic spherules, micrometeorites, meteorites, and astronomical observations.

The most common chemical tracers of extraterrestrial matter in sediments are the siderophile elements, most commonly iridium and other platinum group elements. Physical tracers include cosmic and impact spherules, Ni-rich spinels, meteorites, fossil meteorites, and ocean-impact melt debris. Three types of isotopic systems have been used to trace extraterrestrial matter. Osmium isotopes cannot distinguish chondritic from mantle sources, but provide a useful tool in modeling long-term accretion rates. Helium isotopes can be used to trace the long-term flux of the fine fraction of the interplanetary dust complex. Chromium isotopes can provide unequivocal evidence of an extraterrestrial source for sediments with high concentrations of meteoritic Cr.

The terrestrial history of impacts, as recorded in sediments, is still poorly understood. Helium isotopes, multiple Ir anomalies, spherule beds, and craters all indicate a comet shower in the late Eocene. The Cretaceous-Tertiary boundary impact event appears to have been caused by a single carbonaceous chondrite projectile, most likely of asteroid origin. Little is known of the impact record in sediments from the rest of the Phanerozoic. Several impact deposits are known in the Precambrian, including several possible megaimpacts in the Early Archean.
\end{abstract}

\section{INTRODUCTION}

The discovery of anomalous iridium concentrations in Cretaceous-Tertiary (K-T) boundary sediments (Alvarez et al., 1980) sparked an explosion of research into the study of impacts, biotic extinction events, and relationships between extraterrestrial phenomena and terrestrial ecosystems. One field that has seen enormous growth has been the detection, characterization, and understanding of the extraterrestrial component in sediments. More than a decade ago I wrote a paper on the extraterrestrial component in sediments (Kyte, 1988) that is now hopelessly outdated. This latest paper brings much of this topic up to date. Like the earlier paper, this is meant to be a general (although not comprehensive) review of what has been learned

*E-mail: kyte@igpp.ucla.edu

Kyte, F.T., 2002, Tracers of the extraterrestrial component in sediments and inferences for Earth's accretion history, in Koeberl, C., and MacLeod, K.G., eds., Catastrophic Events and Mass Extinctions: Impacts and Beyond: Boulder, Colorado, Geological Society of America Special Paper 356, p. 21-38. 
about extraterrestrial matter in sediments. It focuses on the different methods that have been developed to detect an extraterrestrial component and the types of interpretations that can be made using these methods. As much as possible, these topics are presented in a historical perspective. There is a brief discussion of the major implications of this work, based on my views. For a discussion of the identification of meteoritic components in impact melt rocks, breccias, and other impactites, see Koeberl (1998).

\section{HISTORICAL BEGINNINGS}

The study of this extraterrestrial component in sediments began with the discovery of cosmic spherules in deep-sea sediments collected during the expedition of the HMS Challenger (1873-1876). Murray and Renard $(1883,1891)$ found that the magnetic fraction of some sediments contained what they called "cosmic dust." These were black magnetic spherules, rarely as large as $200 \mu \mathrm{m}$, and brown spherules, typically $500 \mu \mathrm{m}$. Most of the magnetic fraction could be attributed to volcanic or other terrestrial sources. However, the spherules were unusual; the black magnetic variety had metallic cores and the brown spherules bore a striking resemblance to chondrules, a common component of chondritic meteorites. Murray and Renard (1891, p. 333-336) noted that "while they are universally distributed, they are more abundant in regions where the accumulation of the deposit is relatively slow, and most abundant where the rate of deposition is reduced to a minimum, viz. in the deepest water far removed from continental land." They concluded that these were "extraterrestrial bodies allied to meteorites, and in all probability thrown off by them in their passage through the Earth's atmosphere." In this work, the scientists of the HMS Challenger recognized two important facts: (1) cosmic spherules formed by atmospheric ablation of meteoritic material and (2) the concentration of extraterrestrial material was highest in the most slowly accumulating sediments.

Murray and Renard (1891) cited other work of their time describing possible "cosmic dust." None appeared to be so conclusive in their results as the Challenger work, but they noted that Nordenskjold (1881, cited in Murray and Renard, 1891) collected dust in Greenland in deposits of "Krykonit." These deposits, which occur in lakes on the Greenland ice sheet, are now known to contain some of the best-preserved concentrates of cosmic spherules yet discovered (Maurette et al., 1986). In the succeeding century nearly all work on extraterrestrial matter in sediments concentrated on cosmic spherule studies. This work was mainly descriptive, or focused on new types of deposits in which cosmic spherules could be found, such as Pleistocene beach sands (Marvin and Einaudi, 1967) and Paleozoic salt deposits (Mutch, 1966). One of the first applications of the newly designed electron microprobe was to directly measure the Ni content of magnetic cosmic spherules (Castaing and Fredriksson, 1958), providing the first strong chemical evidence supporting their cosmic origin.
Cosmic spherule science took a major step forward in the 1970s and early 1980s with new collections and refined analyses that directly linked them to specific types of meteorites. This work was largely spearheaded by Don Brownlee and coworkers who were analyzing the source materials of cosmic spherules, i.e., interplanetary dust. In the mid-1970s NASA U-2 aircraft were first used routinely to collect dust in the stratosphere (e.g., Brownlee, 1985). This dust was found to have similarities to some types of chondritic meteorites. Large volume collections of cosmic spherules included use of a magnetic sled dragged on the ocean floor to obtain millions of specimens (Brownlee et al., 1979). Neutron activation analyses of individual spherules (Ganapathy et al., 1978) added Ir to the list of elements indicating a cosmic origin. Scanning electron microscope (SEM) and electron microprobe analyses of stony spherules (the brown spherules of Murray and Renard, 1891) proved that the major element chemistry was similar to that of chondrites and that unmelted relict grains of meteorite minerals could survive atmospheric ablation (Blanchard et al., 1981). The final proof that cosmic spherules had to be of extraterrestrial origin was from the detection of cosmogenic ${ }^{53} \mathrm{Mn}$, a shortlived isotope that can only have formed by irradiation in space (Nishiizumi, 1983).

In addition to the work on cosmic spherules, a number of workers attempted to use chemical methods to determine the flux of cosmic matter to marine sediments. Analyses of the $\mathrm{Ni}$ content of deep-sea sediments and Antarctic ice (Pettersson and Rotschi, 1950; Pettersson and Fredriksson, 1958; Bonner and Lourenco, 1965) yielded what are now known to be erroneously high values. Barker and Anders (1968) used two platinum group elements (PGEs), Ir and Os, to obtain the first reasonable estimate of the long-term flux of extraterrestrial matter. They showed that the concentration of Ir was inversely proportional to the sedimentation rate of slowly accumulating deep-sea clays (Fig. 1). From this relationship they derived an estimate of $60000 \mathrm{t} / \mathrm{yr}$ of cosmic matter accreted to the Earth, a value that has not changed by a factor of two over the past three decades.

The first attempt to use the Barker and Anders (1968) data to measure the accumulation rate of a sediment deposit, based on its Ir concentration, was by Alvarez et al. (1980). The results of this experiment are now almost legend. They found that the Ir concentration of sediments from the K-T boundary were far too high to be from the background influx of cosmic debris, and thus this experiment was a failure; however, it was one of the more spectacular failures in the history of Earth sciences. Alvarez et al. (1980) explained the anomalous Ir concentrations as being due a sudden influx of extraterrestrial matter at the end of the Cretaceous. Their hypothesis was that this influx was due to the impact of an asteroid or comet, $10 \mathrm{~km}$ in diameter, and that the K-T boundary clay was ejecta from this impact. The most exciting aspect of their hypothesis was the speculation that this impact was likely responsible for the mass extinctions recorded at the K-T boundary. The cause of these extinctions had been the subject of controversy for the preceding century, and 


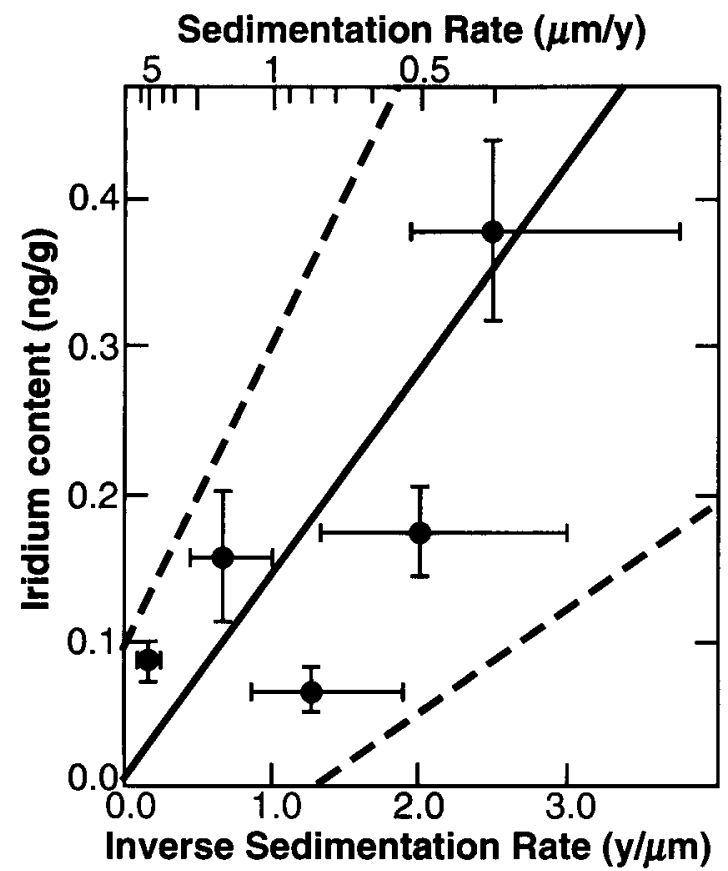

Figure 1. Iridium concentrations in deep-sea sediments are inversely correlated with sediment accumulation rates. Solid line is correlation based on five sediment samples. Dashed lines are $2 \sigma$ uncertainties. After Barker and Anders (1968).

the Alvarez et al. (1980) discovery provided the first extinction hypothesis that was backed up by reproducible physical data and that had testable predictions. Although not precisely 100 yr after the initial discovery of cosmic dust, the discovery of the K-T boundary Ir anomaly, along with modern analyses of cosmic spherules and interplanetary dust, could be considered the start of the second century of research on the extraterrestrial component in sediments.

\section{SOURCES OF EXTRATERRESTRIAL MATTER}

The influx of extraterrestrial materials to the Earth is dominated by two size fractions: submillimeter interplanetary dust and impacting asteroids and comets (Fig. 2; Kyte and Wasson, 1986). The dust is derived from collisions in the asteroid belt and from materials expelled from the surface of comets. To some degree, both the large projectiles and the finest dust have the same two source regions. The modern flux of interplanetary dust, as directly measured from impacts on a satellite collector (Love and Brownlee, 1993), is $30000 \pm 10000 \mathrm{t} / \mathrm{yr}$ (revised from 40000; Engrand and Maurette, 1998). The flux of large impactors is less well known, and must be estimated from analyses of crater statistics and astronomical observations of populations of comets and Earth-crossing asteroids (e.g., Wetherill and Shoemaker, 1982). However, it is generally accepted that most of the mass of extraterrestrial matter accreted to the Earth over geological time scales is from the rare, largest impactors.
The actual composition of these source materials, particularly over long time scales, is uncertain. The modern flux of interplanetary dust could be dominated by recent impacts in the asteroid belt or by a few large, dusty comets. Because dust particles have dynamic lifetimes of only about $10^{5} \mathrm{yr}$ before they spiral into the Sun (Love and Brownlee, 1993), the dust complex can be dominated by just a few source objects at any given time. Although it is generally accepted that meteorites are derived from asteroid belt objects, the well-classified meteorites are probably from no more than 20 asteroids (Dodd, 1989). Astronomical observations of the spectral reflectance of asteroids show that they appear to vary in composition with radial distance from the Sun (Fig. 3; Bell et al., 1989; Shearer et al., 1998). It appears that the outer portion of the asteroid belt is populated by highly carbonaceous asteroids (types $P$ and D) that may be unlike typical meteorites. Direct sampling of comets is limited to flybys of comet Halley, but these have shown that, in addition to the high concentrations of ice in this comet, the dust contains about $30 \%$ carbonaceous matter (e.g., Jessberger and Kissel, 1989).

Interplanetary dust is distinctly different, on average, from typical meteorites. Interplanetary dust particles (IDPs) collected from the stratosphere sample the $5-50 \mu \mathrm{m}$ fraction of the dust complex. These are mostly fine-grained chondritic particles (Brownlee, 1985). The remainder of the dust is typically either melted particles or individual mineral grains. The carbon content of the smaller chondritic IDPs $(\sim 10 \mu \mathrm{m})$, those least heated by atmospheric entry, is typically several times that of the most carbon-rich meteorites (e.g., Brownlee et al., 1997a), so these objects are distinct from most meteorites. Possibly these particles are from the outer asteroid belt or from comets. Larger unmelted dust particles $(50-500 \mu \mathrm{m})$ have been recovered as unmelted micrometeorites from Antarctic melt ice (Engrand and Maurette, 1998). These particles are also much more carbon rich than carbonaceous chondrite meteorites and petrographically they most resemble $\mathrm{CM}$ and $\mathrm{CR}$ chondrites, two relatively rare meteorite groups.

Several attempts have been made to link IDPs to either asteroid or cometary sources (e.g., Klöck et al., 1989; Bradley and Brownlee, 1991). The fine-grained IDPs can generally be classified as belonging to one of two types, smooth or porous (Brownlee, 1985). The smooth IDPs are typically dominated by hydrated clays (e.g., saponite, crondstedite) and are from an object that underwent aqueous alteration (Fig. 4A). The porous IDPs (Fig. 4, B and C) are composed mainly of very fine grained, anhydrous phases, and have been found to contain unusual materials called GEMS (Fig. 4D), an acronym for "glass with embedded metal and sulfides." Because of their apparently amorphous silicates, and possibly heavy radiation damage, these GEMS are considered a likely candidate for unprocessed interstellar materials (Bradley et al., 1999). Detailed studies of the He content of IDPs has been used to model relative velocities of a large number of IDPs in an attempt to distinguish asteroidal from cometary sources (Joswiak et al., 2000). This 
Figure 2. Influx of extraterrestrial matter to Earth is dominated by two size fractions, interplanetary dust and large asteroids and comets. Histogram is after Kyte and Wasson (1986). Dashed curve is adapted from Love and Brownlee (1993).
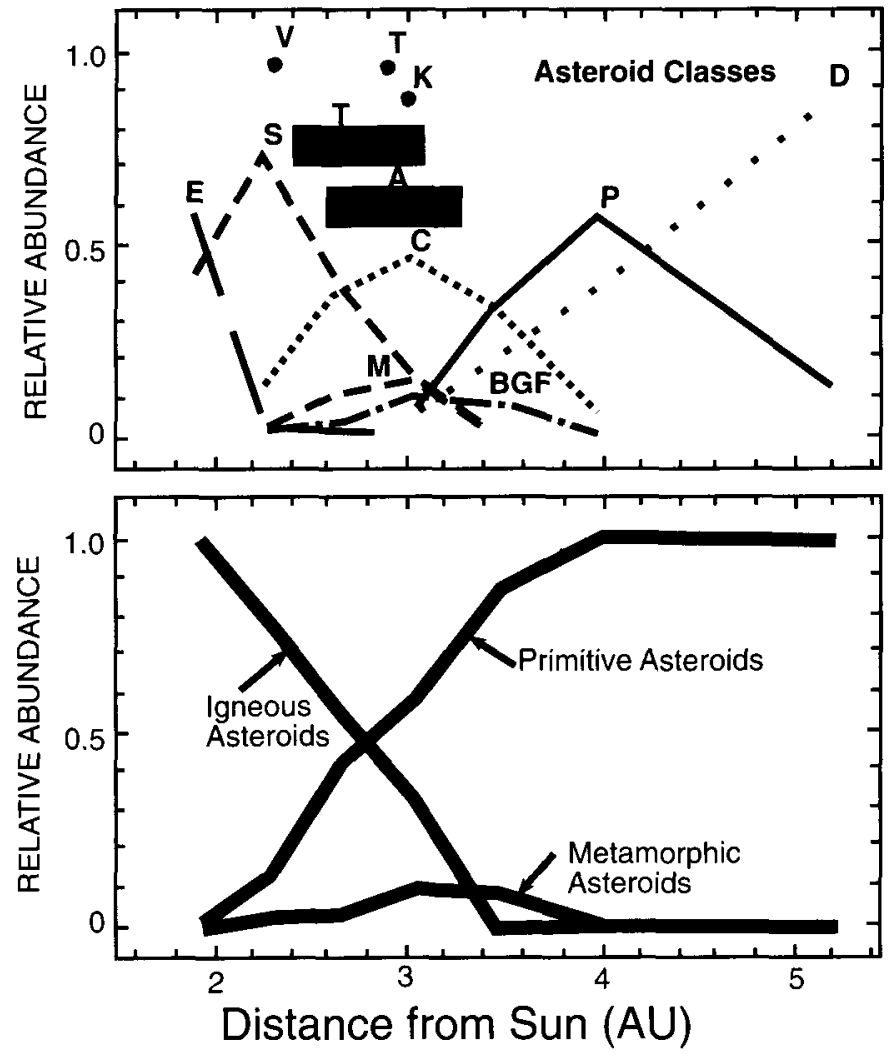

Figure 3. Reflectance spectra of objects in the asteroid belt show that there are several types of asteroids. The outer asteroid belt appears to be dominated by icy carbonaceous chondrites that may not be common in meteorite collections (after Bell et al., 1989).

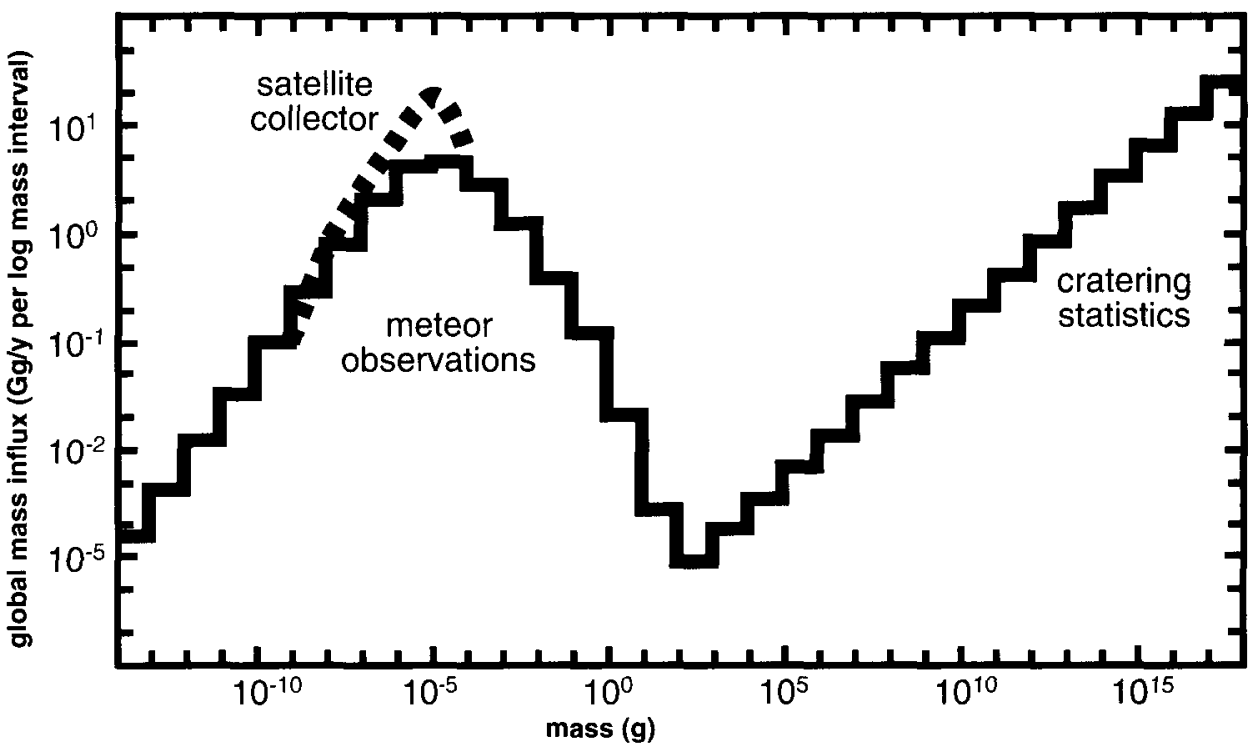

work found that the asteroidal IDPs, having velocities $<14$ $\mathrm{km} / \mathrm{s}$, were dominated by compact particles with hydrated silicates. Cometary IDPs, having velocities $>18 \mathrm{~km} / \mathrm{s}$, were mostly anhydrous, porous types containing GEMS. These data probably present the best criteria for distinguishing cometary from asteroidal materials in interplanetary dust.

\section{TRACERS OF EXTRATERRESTRIAL MATTER IN SEDIMENTS}

The extraterrestrial component in sediments can be traced by three distinct methods: chemical, physical, and isotopic. The most common chemical tracers are the PGEs, of which Ir is the most frequently studied. More recently, fullerenes have been described as potential tracers that may survive even large-body impacts. Physical tracers include actual meteorites, cosmic spherules, impact spherules, spinels derived from either of these rocks, and ocean-impact melt debris. Three isotopic systems, using isotopes of $\mathrm{Os}, \mathrm{He}$, and $\mathrm{Cr}$, have been successfully applied to tracing extraterrestrial matter. Each of these has been successful in examining different aspects of the accretion of meteoritic materials to the Earth. These three types of tracers are discussed in the following.

\section{Chemical tracers}

Siderophile elements. Siderophile elements are those that would be concentrated in a metallic phase, if one were present in a rock. Siderophile elements can be useful tracers of extraterrestrial matter because they are highly depleted in the Earth's crust as a result of both the core-mantle separation early in Earth history (Chou, 1978), and the subsequent mantle-crust fractionation. Siderophiles include the PGEs ( $\mathrm{Ru}, \mathrm{Rh}, \mathrm{Pd}, \mathrm{Os}$, Ir, and 


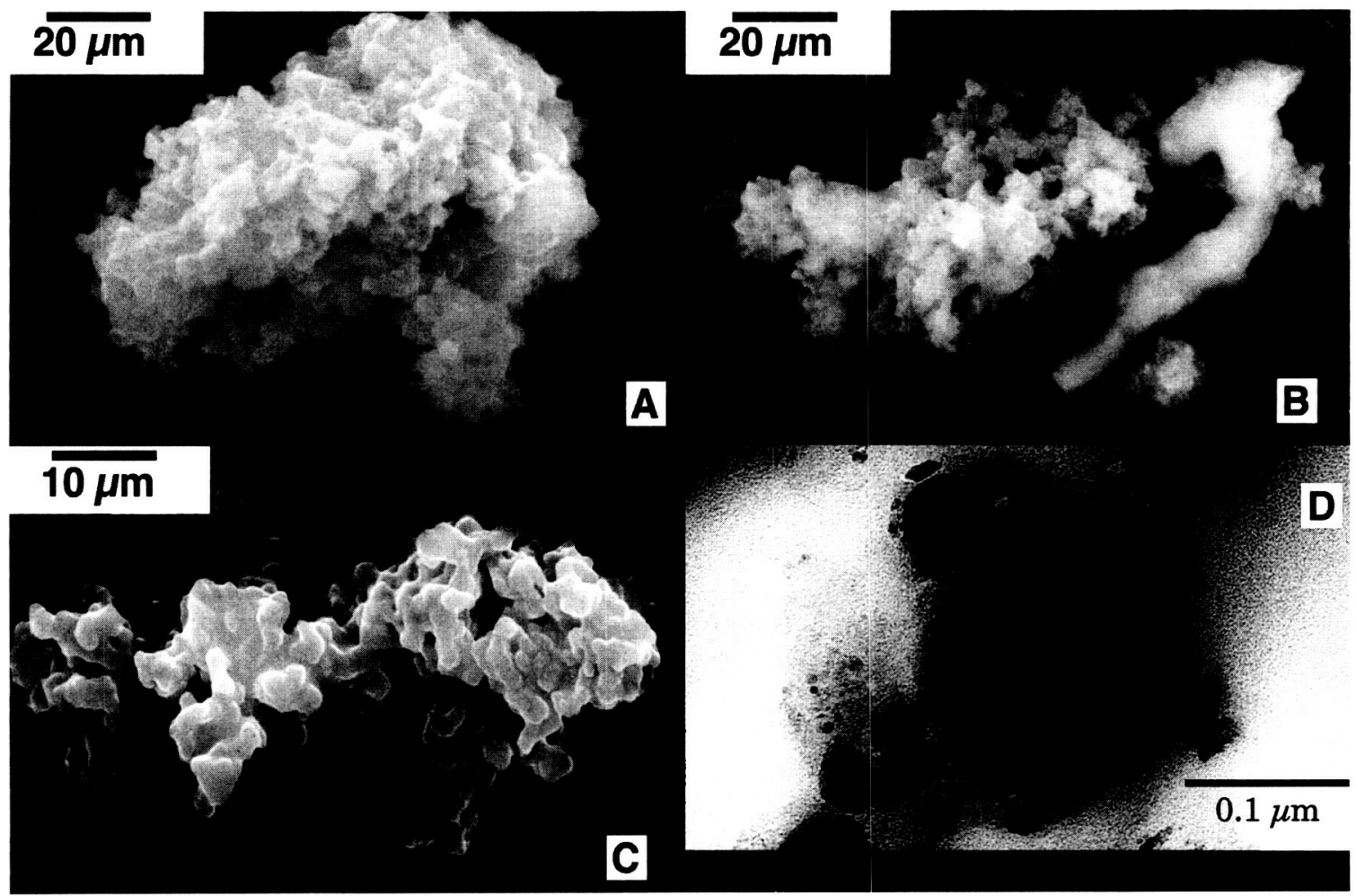

Figure 4. Interplanetary dust particles are routinely collected in the stratosphere. Low-velocity dust particles are probably derived from asteroids. These are commonly compact particles with hydrated silicates (A). High-velocity particles are probably cometary. These are commonly anhydrous porous aggregates (B and C) with GEMS (D; glass with embedded sulfides). Long object in B is probably glass. A-C are secondary electron images. D is transmission electron microscope image. Photos courtesy of D.E. Brownlee.

$\mathrm{Pt}$ ) and $\mathrm{Au}, \mathrm{Re}, \mathrm{Ni}, \mathrm{Co}$, and Fe. Although it is not typically considered a siderophile in meteorites, $\mathrm{Cr}$ is also highly depleted in the crust relative to its concentration in chondritic meteorites, and it can also be a useful measure of extraterrestrial matter. Chromium isotopic studies are discussed in the following. Of the siderophiles, Ir has proven the most commonly used and effective tracer of extraterrestrial matter due to its strong depletion in crustal rocks relative to chondrites (by a factor of $\sim 10^{4}$; Palme et al., 1978) and its relatively easy detection by neutron activation analysis at extremely low concentrations. Recent work in the application of inductively coupled plasma mass spectroscopy to PGE analyses has seen the development of methods for rapid determination of PGEs with detection limits similar to those previously obtainable only by radiochemical neutron activation analyses (Ravizza and Pyle, 1997).

The first successful attempt at using siderophiles as a measure of extraterrestrial matter was that of Barker and Anders (1968), who measured Ir and Os concentrations in slowly accumulating deep-sea clays. They used this to calculate an extraterrestrial matter accretion rate that is little changed to this date (e.g., Kyte and Wasson, 1986; Peucker-Ehrenbrink, 1996). The Barker and Anders (1968) study is attributed as the basis for the Ir measurements performed by Alvarez et al. (1980) that led to the discovery of the K-T boundary Ir anomaly. Shortly after the discovery of the K-T Ir anomaly, other workers found anomalies for Os (Smit and Hertogen, 1980), as well as other PGEs, Re, and Au (Ganapathy, 1980; Kyte et al., 1980). The other PGEs were all found to have interelemental abundances roughly similar to those in chondrites. This was considered to be another strong argument for a meteoritic signature in $\mathrm{K}-\mathrm{T}$ boundary sediments.

In succeeding years, a number of workers used abundances of a number of PGEs and siderophiles to argue for an extraterrestrial provenance for K-T boundary sediments (e.g., Smit and Kyte, 1984; Gilmore et al., 1984; Kyte et al., 1985). Although this work showed that interelement abundances for siderophiles were similar to those in chondritic meteorites, there were fractionations noted by other workers. For example, Tredoux et al. (1989) argued that PGE abundances were different between Northern and Southern Hemisphere K-T boundary sites, and that this might best be explained by a mantle-derived source for the PGEs. Evans et al. (1993) argued that differences in the ratio of $\mathrm{Ru} / \mathrm{Ir}$ between $\mathrm{K}-\mathrm{T}$ sites in North America and Europe was a primary feature, related to the relative volatilities of these two elements and their condensation from an impact-generated vapor plume. Evans et al. (1993) argued that the $\mathrm{Ru} / \mathrm{Ir}$ ratio 
should increase with increasing distance from the impact crater. In retrospect, while it is now relatively clear that the PGEs in K-T boundary sediments were probably largely derived from the Chicxulub projectile, the specific physical and chemical processes involved in their transfer to sediments, as well as their final preservation in K-T boundary clays, are still poorly understood.

Immediately following the Alvarez et al. (1980) discovery, additional Ir anomalies were linked to other likely impact deposits. Anomalous Ir was inadvertently discovered by Crocket and Kuo (1979), actually predating the K-T boundary discovery, in a sample of late Pliocene sediment from USNS Eltanin sediment core E13-3. However, the significance of this anomaly was not recognized until Kyte et al. (1981) studied the core in greater detail. Subsequent work has now thoroughly documented this as a signal from the Eltanin asteroid impact (e.g., Gersonde et al., 1997). Ganapathy (1982) found an Ir anomaly in late Eocene sediments closely associated with microtektite deposits. The confirmation of this anomaly as being stratigraphically below the microtektite horizon (Sanfilippo et al., 1985) led to the understanding that late Eocene clinopyroxene spherules were from a separate impact event, actually predating the impact that produced the microtektites (Glass et al., 1985; Glass and Burns, 1987).

The excitement surrounding the possible extraterrestrial cause of the K-T boundary extinctions led to speculation that many other mass extinctions might have been caused by impacts. When Raup and Sepkoski (1984) found an apparent periodicity in the frequency of mass extinctions, several astronomical mechanisms were proposed that could cause periodic perturbations of the Oort Cloud, a symmetric cloud of comets extending to interstellar distances (Weissman, 1985). These mechanisms for causing periodic comet showers included perturbations by a dark companion star to the Sun (Whitmire and Jackson, 1984; Davis et al., 1984), giant molecular clouds encountered as the solar system oscillates through the galactic plane (Rampino and Stothers, 1984), and an unobserved tenth planet (Whitmire and Matese, 1985).

This excitement was largely followed by disappointment as extensive searches of numerous extinction horizons (summarized by Orth et al., 1985; Kyte, 1988) found no strong evidence to link them to extraterrestrial factors. Reports of an Ir anomaly at the Permian-Triassic (P-T) boundary (Xu et al., 1985) lent some hope after earlier work proved negative (Asaro et al., 1982; Alekseev et al., 1983), but subsequent work failed to confirm this (Clark et al., 1986; Zhou and Kyte, 1988). Retallack et al. (1998) described deformed and possibly shocked quartz in P-T sediments, but a possible extraterrestrial event at this greatest mass extinction remains unproven. Several reports of spherules in Late Devonian sediments (e.g., Wang, 1992; Claeys and Cassier, 1994) been were intriguing, but detection of any clearly defined extraterrestrial component, such as a strong Ir anomaly, has remained elusive (e.g., Mc Ghee et al., 1985; Claeys et al., 1996). In my opinion, no mass extinction other than that at the K-T boundary has been conclusively linked to a strong extraterrestrial signature.

A significant extraterrestrial component has been detected in several Precambrian deposits. Late Precambrian ejecta found in Australian shales that contain shocked minerals and rocks are probably derived from the Acraman impact structure (Gostin et al., 1986; Williams, 1986). These deposits have anomalous Ir and other PGEs (Gostin et al., 1989; Wallace et al., 1990). Small Ir anomalies have been found in at least two of four known spherule deposits from the Hamersley basin of western Australia (Simonson et al., 1998), and anomalous PGEs in addition to Ir have been found in a Late Archean spherule layer in South Africa (Simonson et al., 2000). These reports all lend significant credence to interpretations of an impact origin for these multiple spherule deposits.

Perhaps the most spectacular deposits with a large extraterrestrial component are found in the Early Archean (3.2-3.5 Ga) Barberton Greenstone Belt, South Africa. Lowe et al. (1989) identified at least four spherule beds with thicknesses ranging from $\sim 10$ to $100 \mathrm{~cm}$. They cited several criteria that distinguish these beds from typical volcanic and clastic sediments, including (1) wide geographic distribution in a variety of depositional environments, (2) relict quench textures, (3) absence of juvenile volcaniclastic debris, and (4) extreme enrichment of Ir and other PGEs. However, some workers argue for a terrestrial origin, possibly related to volcanism and gold mineralization (e.g., Koeberl et al., 1993; Koeberl and Reimold, 1995). Perhaps the strongest arguments, by Koeberl and Reimold (1995), are the extreme enrichments of Ir in these rocks and the proximity of some spherule bed localities to rocks with strong gold mineralization. A few individual samples from within these beds contain Ir concentrations equal to or higher than those in chondrites. The average content of extraterrestrial matter in these beds (based on PGE abundances) is probably 10\%-20\% by weight (e.g., Koeberl and Reimold, 1995; Shukolyukov et al., 2000a). These are very high concentrations, but comparable extremes have been observed in K-T boundary sediments (on a carbonate-free basis; e.g., Kyte et al., 1980; Schmitz, 1988), and in materials concentrated from K-T boundary sediments (Robin et al., 1993; Kyte, 1998).

In a detailed study of PGE abundances in one of these spherule beds (bed S4), Kyte et al. (1992) found strong correlations between Ir, Pt, Os, Pd, and $\mathrm{Au}$ in a set of 15 samples that had absolute PGE concentrations that varied by an order of magnitude. Average elemental ratios based on correlations for Os/Ir and $\mathrm{Pt} / \mathrm{Ir}$ were $\sim 0.8$ times those ratios in CI chondrites (Fig. 5). This is a remarkable agreement, considering analytical uncertainties of at least $10 \%$ and the fact that these rocks had undergone early hydrothermal metamorphism that completely replaced primary impact minerals with chlorite and quartz. They found that Pd was depleted and Au was strongly depleted relative to chondrites, $\mathrm{Pd} / \mathrm{Ir}$ and $\mathrm{Au} / \mathrm{Ir}$ being 0.41 and 0.02 times CI, respectively. Kyte et al. (1992) pointed out that of these five siderophiles, $\mathrm{Au}$ and to a lesser extent $\mathrm{Pd}$, are known to be the 

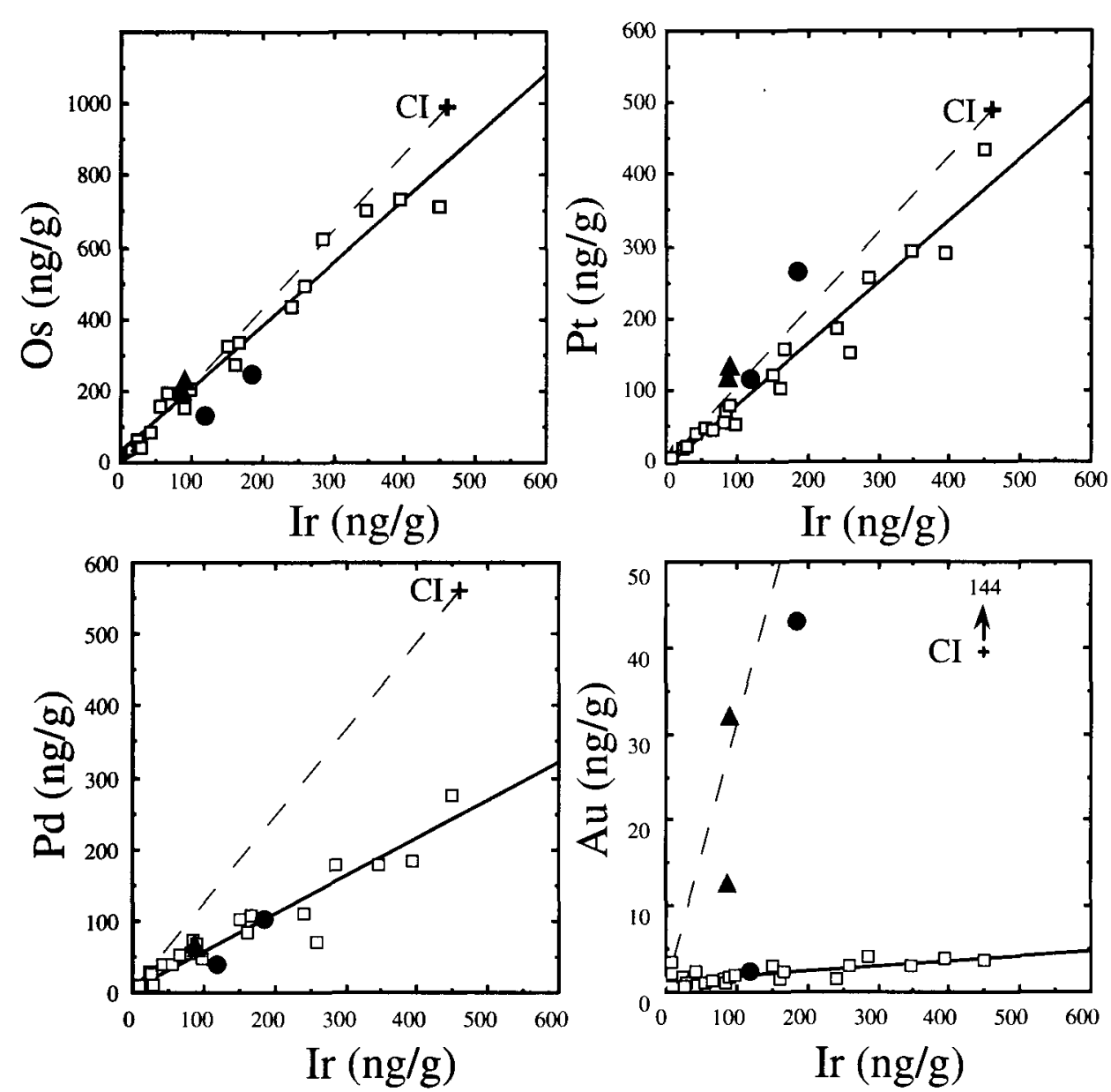

Figure 5. Plots of Os, Pt, Pd, and Au vs. Ir in samples from three Early Archean spherule beds: 15 samples from bed $\mathrm{S} 4$ (open squares) are strongly correlated (solid line). Ratios for $\mathrm{Os} / \mathrm{Ir}$ and $\mathrm{Pt} / \mathrm{Ir}$ are close to those ratios in $\mathrm{CI}$ chondrites (dashed line and cross). Samples from beds S3 (black circles) and S2 (gray triangles) also have abundances similar to those in chondrites, except for $\mathrm{Au}$ in one sample. After Kyte et al. (1992). most mobile during alteration. They argued that this pattern of high concentrations of Ir, Os, and Pt at chondritic abundances with depleted $\mathrm{Pd}$ and $\mathrm{Au}$ is consistent with an original chondritic source that had been altered by secondary processes. This is the opposite of the pattern that one would expect due to gold mineralization, which would result in deposits highly enriched in $\mathrm{Au}$ and $\mathrm{Pd}$ relative to other siderophiles.

This pattern of $\mathrm{Au}$ and $\mathrm{Pd}$ enrichment that Kyte et al. (1992) predicted should be caused by mineralization was observed in a study of another Early Archean spherule bed. Reimold et al. (2000) reported detailed analyses of PGEs and Au in a number of samples from the Princeton Mine, South Africa. These included a number of samples from spherule bed $\mathrm{S} 2$ as well as samples from rocks that were heavily mineralized. Most of their spherule bed samples had chondritic interelement abundances for Ir, Ru, Rh, and Pt, but variable abundances for Pd and $\mathrm{Au}$. The latter elements were both either somewhat depleted or enriched relative to chondritic interelement abundances. In contrast, the rocks that had undergone high levels of $\mathrm{Au}$ mineralization had more fractionated PGE abundances (relative to chondrites) at much lower concentrations than in the spherule beds. These mineralized samples also had moderate enrichment of $\mathrm{Pd}\left(\sim 5\right.$ times) and extreme enrichment of $\mathrm{Au}$ (to $10^{4}$ times) relative to the other PGEs. Reimold et al. (2000) remained highly skeptical of an extraterrestrial origin for this PGE anomaly, noting the extreme enrichment of Ir in a few samples, as well the fact that a few samples that did not contain spherules also had high Ir concentrations. However, arguments of terrestrial versus extraterrestrial origin for these beds may soon be moot. Recent analyses of $\mathrm{Cr}$ isotopes have confirmed the extraterrestrial nature of the siderophile anomaly, at least in bed S4 (Shukolyukov et al., 2000a). This method should soon resolve this question in the other spherule beds, and allow future studies to work on unraveling the nature of extraterrestrial and terrestrial processes that cause such large PGE enrichments.

Fullerenes. Fullerenes $\left(\mathrm{C}_{60}\right.$ and $\left.\mathrm{C}_{70}\right)$ have been reported in K-T boundary sediments (Heymann et al., 1994; Becker, 2000 ) and in breccias from the $1.85 \mathrm{Ga}$ Sudbury impact structure (Becker et al., 1994). The origin of these fullerenes was originally attributed to K-T boundary wildfires (Heymann et al., 1994) or formation within the impact plume (Becker et al., 1994). However, ${ }^{3} \mathrm{He}$ has now been reported in fullerenes from both of these deposits (Becker et al., 1996; Becker, 2000), and it has been suggested that the fullerenes might also be of extraterrestrial origin. If so, fullerenes would represent a new type of tracer of extraterrestrial matter. However, another study of 
the Sudbury breccia (Mukhopadhyay et al., 1998) contradicted these results, and concluded that all ${ }^{3} \mathrm{He}$ in these rocks could be attributed to decay of ${ }^{6} \mathrm{Li}$. Further work is needed to evaluate the potential of this method before it can be accepted as a routine tracer of extraterrestrial matter in sediments.

\section{Physical tracers}

Cosmic and impact spherules. These two types of spherules are discussed together because in some cases it is not possible to distinguish them. Spheroidal material has been described in numerous settings, but much of this work includes spherules of unproven meteoritic or even impact origin. For this reason, in this section I concentrate on well-documented occurrences of spherules that contain a significant meteoritic component.

Cosmic spherules are derived primarily from atmospheric ablation of interplanetary dust grains. Murray and Renard (1983) originally distinguished two types, black magnetic spherules and brown chondrule-like spherules. The chondrulelike spherules are now referred to as stony, and have a roughly chondritic major element composition (e.g., Brownlee et al., 1997b). These are by far the most abundant type of cosmic spherule. The black spherules are composed of oxides of Fe (magnetite, wüstite, hematite), often with a core of metallic $\mathrm{NiFe}$. Although they clearly had a metallic precursor, a large fraction of the black magnetic type is almost certainly derived from chondritic metal, rather than from iron meteorites (Herzog et al., 1999). Thus, the bulk composition of most of the materials that make up the cosmic spherules is chondritic in origin. Detailed analyses of the major element chemistry of the stony spherules shows that they have compositions that are on average similar to type CM chondrites (Brownlee et al., 1997b), although they are depleted in volatiles $(\mathrm{Na}, \mathrm{S})$ due to atmospheric heating and depleted in siderophiles by a less understood mechanism, possibly due to separation of immiscible phases during melting in the atmosphere.

Cosmic spherules are now known from a wide range of environments and ages. These include recent deep-sea sediments, Pleistocene beach sands (Marvin and Einaudi, 1967), mid-Cenozoic clays (Taylor and Brownlee, 1991; Kyte and Bostwick, 1995), Jurassic hardgrounds (Czajkowski, 1987; Jehanno et al., 1988), Silurian and Permian salt deposits (Mutch, 1966), and Proterozoic red sandstones (Kettrup et al., 2000). It is now well established that silicate spherules are poorly preserved in deep-sea sediments and new types of spherules have been discovered in less corrosive environments, such as blue lakes in Greenland (Maurette et al., 1986; Robin, 1988; Taylor and Brownlee, 1991). The most spectacular and well-preserved cosmic spherule collections have come from a water well at the South Pole (Taylor et al., 2000). This collection includes a full range of particles, from totally melted spherules (including types never described before) through unmelted micrometeorites, and represents the best collection to date of samples from the coarse fraction of the interplanetary dust complex.
Most impact spherules probably do not contain a significant extraterrestrial component, so, although they may be tracers of impact events, they are not necessarily tracers of meteoritic materials. Microtektite deposits are well known for having extremely low Ir concentrations (e.g., Schmidt et al., 1993). The common interpretation of this is that there is an extremely low concentration of meteoritic matter in the ejecta. Thus, the microtektites are composed almost entirely of terrestrial impact target materials. Glass and Koeberl (1999) reported Ir concentrations as high as $0.3 \mathrm{ng} / \mathrm{g}$ in late Eocene microtektites, but this is $<0.1 \%$ of the concentration in chondritic meteorites ( $\sim 580 \mathrm{ng} / \mathrm{g}$ on a volatile-free basis).

Late Eocene clinopyroxene-bearing spherules are associated with a significant Ir anomaly (e.g., Sanfilippo et al., 1985; Glass and Koeberl, 1999; Vonhof and Smit, 1999). Unfortunately, no analyses of Ir have been reported for the clinopyroxene spherules. However, Glass and Koeberl (1999) cited a Ni/ Ir ratio of $10^{6}$ from $\mathrm{R}$. Ganapathy (1983, personal commun.). Glass and Koeberl (1999) measured Ni concentrations up to 4 $\mathrm{mg} / \mathrm{g}$ in clinopyroxene spherules from Ocean Drilling Program Site 689 , so one can infer that clinopyroxene spherules have an Ir content of $\sim 4 \mathrm{ng} / \mathrm{g}$. This is a significant concentration of Ir, but still $<1 \%$ of chondritic abundances and an insufficient amount to account for the Ir deposited at this site. The peak concentration of clinopyroxene spherules found at Site 689 by Glass and Koeberl (1999) was $<30$ spherules per gram of sediment. These small particles $(\sim 100 \mu \mathrm{m})$ cannot possibly be the carrier of the Ir in sediments in which Montanari et al. (1993) found bulk Ir concentration of $0.16 \mathrm{ng} / \mathrm{g}$.

Many types of spherules are known in K-T boundary sediments, but most are probably not the principal carrier of Ir and other meteoritic components. Large spherules composed of a tektite-like glass occur in regional deposits near the Chicxulub impact structure, in Haiti, and in the base of tsunami deposits along the Gulf of Mexico (e.g., Smit 1999). These tektites may also be the source of the lower clay layer of the impact couplet in the North American interior (e.g., Bohor and Glass, 1995). They are not a significant carrier of the global Ir anomaly (e.g., Rocchia et al., 1996). The main carrier of the extraterrestrial component in K-T boundary sediments is in the global ejecta, which compose the uppermost layer of sediments in regional deposits near Chicxulub (Smit, 1999). This layer is also mostly composed of spherules, and Smit (1999) estimated the spherule concentration to be $\sim 20000 / \mathrm{cm}^{2}$. At least three types of spherules have been described from the global K-T layer (Montanari et al., 1983; Smit et al., 1992). Spherules composed largely of glauconite or potassium feldspar have similar dendritic textures, which Smit et al. (1992) suggested may be derived from clinopyroxenes. Spherules containing unaltered clinopyroxene have only been observed in the K-T boundary from the North Pacific Deep Sea Drilling Project (DSDP) Site 577. Smectitic spherules containing an Ni-rich, magnesioferrite spinel are known from a number of sites around the world (e.g., Kyte and Smit, 1986; Kyte and Bostwick, 1995). 
Only the spinel-bearing spherules are clearly established as an important carrier of the siderophile-element anomaly in K-T boundary sediments. Montanari et al. (1983) measured 68 $\mathrm{ng} / \mathrm{g}$ Ir in magnetic concentrates of spherules from Petriccio, Italy. This was nearly an order of magnitude greater than the 8 $\mathrm{ng} / \mathrm{g}$ Ir of the bulk sediment. By contrast, K-feldspar spherules contained $1 \mathrm{ng} / \mathrm{g}$ Ir and glauconitic spherules were $<2 \mathrm{ng} / \mathrm{g}$ Ir. Smit and Kyte (1984) also showed that the Italian spinelbearing spherules had element//r ratios for $\mathrm{Pt}, \mathrm{Au}$, and $\mathrm{Pd}$ that were within a factor of two of those ratios in chondritic meteorites. The conclusion was that these spherules contained $\sim 10 \%$ chondritic materials. In a similar study of spinel-bearing spherules from North Pacific DSDP Site 577, Robin et al. (1993) analyzed individual spherules. Their average concentration of $84 \mathrm{ng} / \mathrm{g}$ Ir is comparable to, but somewhat higher than, the values measured in Italy. Robin et al. (1983) found that a few individual spherules had concentrations as high as $610 \mathrm{ng} /$ g Ir, comparable to levels in chondritic meteorites.

There is some disagreement as to the actual source of the spinel-bearing spherules. Robin et al. (1993) argued that they are derived directly from meteoritic materials by atmospheric ablation related to localized impact events. Rocchia et al. (1996) proposed that this might have resulted from reentry of projectile material that was ricocheted from the Chicxulub crater during a low-angle impact event. Whereas a direct meteoritic source may be the only reasonable interpretation of the very Ir-rich particles, Kyte and Bostwick (1996) argued that the regional variability of spinel compositions and textures are best explained by formation of spherules within the impact plume, possibly by condensation from the impact vapor. Competing hypotheses of formation of spinel-bearing spherules as individual ablation droplets (Gayraud et al., 1996) or vapor condensates (e.g., Kyte and Bostwick, 1985; Ebel and Grossman, 1999) have yet to be resolved. However, an undisputed fact is that these particles are an important carrier of meteoritic materials in K-T boundary sediments.

Several other occurrences of spherules that are likely carriers of a significant extraterrestrial component have been documented. Spinel-bearing spherules were produced by the late Pliocene oceanic impact of the Eltanin asteroid (Margolis et al., 1991; discussed further in the following). Spinel-bearing spherules from a late Eocene Ir anomaly in sediments from Massignano, Italy, were described as ablation particles formed from a comet impact (Pierrard et al., 1998). However, there are no specific Ir data on these spherules, and it is not clear that it is possible to distinguish them from clinopyroxene spherules found in other late Eocene deposits (e.g., Glass and Koeberl, 1999; Vonhof and Smit, 1999), which cannot be the main carrier of Ir in these deposits. Unusual spinel-bearing spherules from a Jurassic hardground (Jehanno et al., 1988) have Ir contents averaging $300 \mathrm{ng} / \mathrm{g}$ and include individuals with unusual, compound spherule shapes. Presumably they formed by accretion of multiple droplets in flight. The only known analogue to this is compound spherules formed by the Eltanin impact (Margolis et al., 1991). Jehanno et al. (1988) inferred that the Jurassic spherules all formed in a single large accretionary event. Spherules are also known in several layers in Proterozoic and Late Archean sediments, several of which contain small Ir anomalies (e.g., Simonson et al., 2000; Simonson and Harnik, 2000). Perhaps the most spectacular spherule deposits are those found in Early Archean sediments (e.g., Lowe et al., 1989), which are discussed herein.

Spinels. Ni-rich magnesioferrite spinels are known to occur in many types of spherules, including cosmic spherules (e.g., Robin et al., 1992) and impact spherules such as at the K-T boundary (Smit and Kyte, 1984), in Eltanin ejecta (Margolis et al., 1991), and even in an Archean spherule bed (Byerly and Lowe, 1994). These spinels are often considered to be hightemperature phases that have survived diagenetic alteration and record processes involved in formation and evolution of at least one K-T boundary component (e.g., Kyte and Smit, 1986; Robin et al., 1992; Kyte and Bostwick, 1995). Very little is known about the trace element chemistry of these spinels. Bohor et al. (1986) measured $29 \pm 11 \mathrm{ng} / \mathrm{g}$ Ir in spinels from the K-T boundary at Carvaca, Spain, less than the bulk Ir content of the Caravaca boundary clay (52 ng/g; Bohor et al., 1986). Therefore, although the spinel has an extraterrestrial component, it cannot be the principal carrier of Ir at this site. $\mathrm{Ni}, \mathrm{Cr}$, and a significant fraction of other major elements (e.g., Mg, Fe, Al) in these spinels may be derived directly from meteoritic precursors.

Unfortunately, the silicate portion of the spherules from which these spinels crystallized does not survive alteration. At best, the silicates are preserved as clays with relict textures (e.g., Montanari et al., 1983; Robin et al., 1993), but they often fall apart during sample processing and only individual spinels can be extracted from sediment. In the latter case, spinels can be used as a proxy tracer of extraterrestrial matter that was originally contained in spherules.

At many K-T boundary sites, individual spinel grains have served as useful tracers of the physical debris deposited by the impact event (Bohor et al., 1986; Zhou et al., 1991; Robin et al., 1991; Rocchia et al., 1996). An important point raised by Robin et al. (1991) is that in K-T boundary sediments, the distribution of physical tracers such as spinels can be quite different from chemical tracers such as Ir. Whereas the stratigraphic distribution of spinels can be influenced only by physical processes such as reworking or bioturbation, Ir can be mobilized by diagenesis and can diffuse through sediment pore waters (e.g., Wallace et al., 1990; Colodner et al., 1992; Evans et al., 1993). At different K-T boundary sites, Robin et al. (1991) found that spinels are always restricted to a narrow stratigraphic interval, while the Ir signal is always dispersed, probably as a result of postdepositional chemical processes (Fig. 6). These results provide a strong argument for a single, geologically brief $(<100 \mathrm{yr})$, accretionary event at the K-T boundary that deposited physical ejecta and was followed by chemical diffusion during diagenesis. 


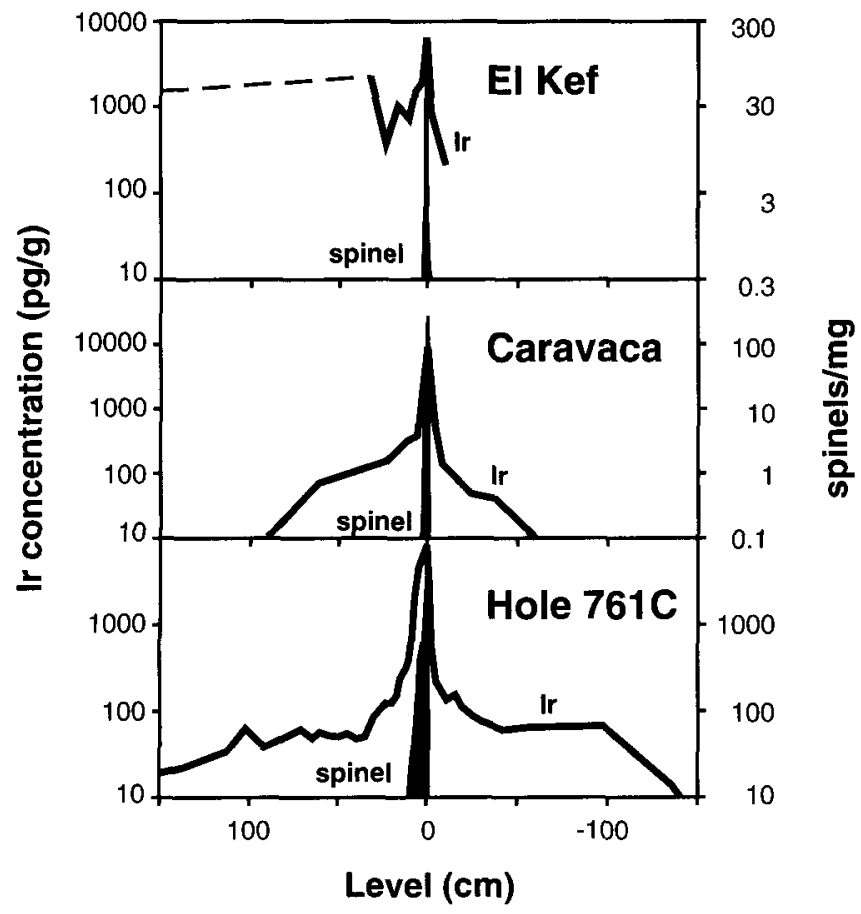

Figure 6. Ir anomaly in Cretaceous-Tertiary boundary sediments can be quite broad, extending into sediments below horizon. However, physical ejecta such as spinels are restricted to very thin stratigraphic interval. After Robin et al. (1993).

The stratigraphic distribution of spinels is being examined in LL44-GPC3, a large-diameter piston core of pelagic clay from the central North Pacific. This core contains a relatively complete record of sediment accumulation since the Late Cretaceous (Kyte et al., 1993). Preliminary results from Robin et al. (1999) indicate that at least five horizons contain anomalous concentrations of spinels. One of these is at the K-T boundary, two are from the middle Cenozoic, and two are from the Pleistocene. Robin et al. (1999) attributed these to impact events, but provided no specific criteria to distinguish these as impact spherules, as opposed to cosmic spherules. At least one of the middle Cenozoic horizons, at $11.2 \mathrm{~m}$ depth, also contains abundant spherules that were studied by Kyte and Bostwick (1995) and interpreted as cosmic spherules. This is also nearly coincident with a peak in extraterrestrial ${ }^{3} \mathrm{He}$, centered at $11.4 \mathrm{~m}$ depth in LL44-GPC3 (Farley, 1995). One of these middle Cenozoic, spinel-rich horizons probably correlates with the spinelrich horizon in Massignano, Italy (Pierrard et al., 1998). Whether these spinel horizons are impact deposits, or the result of other types of accretionary events, they are valuable tracers of the flux of extraterrestrial matter to deep-sea sediments.

Meteorites. Recovery of actual meteorites provides the best information about the composition of extraterrestrial matter accreted to Earth, because they can be directly compared to potential source materials. Meteorites and fossil meteorites have been described in a number of deposits. Meteorites have been recovered from two hypervelocity impacts, the Eltanin oceanic and the K-T boundary events. Micrometeorites are now routinely recovered in cosmic spherule collections (Engrand and Maurette, 1998; Taylor et al., 2000).

The first fossil meteorite found in ancient sediments was Brunflo, a heavily altered $10 \mathrm{~cm}$ chondrite found in Ordovician limestone (Thorslund et al., 1981, 1984). Relict textures are well preserved, but nearly all the precursor minerals in this meteorite were replaced by calcite, clays, and other trace phases. Only chromites appear to retain their original chemistry, and these are used to infer that this meteorite was an H-type, ordinary chondrite. Schmitz et al. (1996) recovered 13 additional fossil meteorites from these strata, and proposed that the accumulation rate of these meteorites and Ir in associated sediments is higher than in modern sediments and that this is evidence of a large collision in the asteroid belt during the Ordovician.

Numerous meteorite fragments are found in the ejecta layer of the Eltanin impact event (Kyte and Brownlee, 1985; Gersonde et al., 1997; Kyte, 2002a, 2002b). These are typically a few millimeters in size, but one individual as large as $1.5 \mathrm{~cm}$ was recovered. Although most of the coarse ejecta from the Eltanin impact is melted asteroidal materials (discussed in the following), $\sim 7 \%$ survived as unmelted meteorites. The meteorites recovered in deposits of the Eltanin impact are polymict breccias composed mainly of plagioclase and pyroxene with compositions similar to those found in basaltic meteorites; specifically the howardites and the silicates of mesosiderites. Because of relatively high Ir concentrations in the Eltanin impact melt (Kyte and Brownlee, 1985; Kyte, 2000c), the Eltanin asteroid is inferred to be related to mesosiderites, meteorites containing both basaltic and metallic components (e.g., Mittlefehldt et al., 1998). These meteorite fragments provide conclusive evidence that the Eltanin projectile was from an asteroidal, rather than a cometary source.

Meteoritic materials have also been described in K-T boundary sediments. Robin et al. (1993) inferred that irregular particles with spinel-rich rims and high Ir concentrations from the K-T boundary at DSDP Site 577 may be partially melted meteoritic debris. These particles are $\sim 250 \mu \mathrm{m}$ in size, and no relict meteorite textures or minerals have been described, but Robin et al. (1993) pointed out that similar objects occur as partially melted meteorites in cosmic spherule collections. At a nearby locality in the western North Pacific, DSDP Site 576, Kyte (1998) recovered a $2.5 \mathrm{~mm}$ fossil meteorite in the K-T boundary. This specimen has chondritic concentrations of Ir, $\mathrm{Fe}$, and $\mathrm{Cr}$, as well as relict mineral textures that were interpreted to be from olivine, metal, sulfides, and a fine-grained clay matrix. The clay mineral saponite, which is common in some carbonaceous chondrites (Zolensky et al., 1993) and IDPs (Joswiak et al., 2000), was also found. On the basis of these data, Kyte (1998) inferred that the K-T bolide had characteristics similar to those of many carbonaceous chondrites, with olivine, metal and sulfide in a fine-grained, phyllosilicate-rich 
matrix. On the basis of the abundances of these phases in this small specimen, it was inferred to be most like the $\mathrm{CO}, \mathrm{CV}$, and $\mathrm{CR}$ groups of chondrites. Notably, because the K-T meteorite appeared to be from a compact, hydrated object, rather than a porous, anhydrous one, Kyte (1998) favored an asteroidal source over a cometary one for the K-T projectile. This is consistent with interpretations of provenance for stratospheric IDPs discussed herein (Joswiak et al., 2000).

Ocean impact melt products. Deep-ocean impacts of small asteroids or comets can produce a unique class of meteoritic debris. This is because smaller projectiles cannot penetrate several kilometers of water. In effect, the projectile will not mix with silicates from the ocean floor, and melt products will be composed almost entirely of meteoritic materials. There may also be a similar type of meteoritic materials that are produced by objects that cannot penetrate the atmosphere (i.e., atmospheric impacts), but no extraterrestrial materials from such an event have been documented. A classic example of an atmospheric impact is the Tunguska event of 1908. No unequivocal evidence of an extraterrestrial deposit from this event is known (Zahnle, 1996). Chyba et al. (1993) proposed that the Tunguska explosion was caused by catastrophic disruption of a small stony asteroid in the upper troposphere. The ability of a projectile to penetrate the atmosphere and impact the ocean is a function of its strength, size, velocity, and impact angle (Chyba et al., 1993). For stony asteroids, minimum diameters of a few hundred meters may be required for projectiles to penetrate the atmosphere and impact the ocean surface with cosmic velocities.

Numerical simulations of deep-ocean impacts (Artemieva and Shuvalov, 2002) provide some limits on the size of a projectile that will not mix with the ocean floor during a deepocean impact. For a vertical impact at asteroidal velocities $(\sim 20$ $\mathrm{km} / \mathrm{s}$ ), mixing is only likely when the projectile diameter is greater than $1 / 2$ of the water depth. For oblique impacts, even larger projectiles will not mix with the ocean floor. Given the typical water depths of 4-5 km in deep-ocean basins, asteroidal projectiles with diameters as large as 2 or $3 \mathrm{~km}$ may commonly produce silicate ejecta composed only of meteoritic materials and seawater salts. However, the compressed water column beneath the projectile can still disrupt and shock metamorphose the ocean floor. Given that $60 \%$ of the Earth's surface is covered by oceanic lithosphere and $500 \mathrm{~m}$ projectiles hit the Earth on $10^{5} \mathrm{yr}$ time scales (Wetherill and Shoemaker, 1982), there must be hundreds of oceanic impact deposits in the sediment record to be discovered.

The only known case of a deep-ocean impact event is the late Pliocene impact of the Eltanin asteroid. This was originally discovered as an Ir anomaly in a sediment core from the subAntarctic Pacific (Kyte et al., 1981). Ejecta from this impact is now known from at least eight sediment cores across at least $500 \mathrm{~km}$ of the ocean floor (Kyte et al., 1988; Gersonde et al., 1997; Kyte, 2002a). Most of the ejecta is a vesicular melt rock composed mostly of asteroidal materials (Fig. 7, A-C; Kyte and
Brownlee, 1985). The only terrestrial component in the ejecta is a few percent $\mathrm{Na}, \mathrm{K}$, and $\mathrm{Cl}$ from seawater salts, the least volatile component of the impact target. The salt component is clear evidence that the asteroid actually mixed with a seawater target. The high vesicularity of the melt is presumably produced by water vapor escaping from the melt. On the basis of the composition of meteorite fragments that compose several percent of the ejecta, as well as the content of $\mathrm{Ir}, \mathrm{Ni}$, and $\mathrm{Fe}$ in the melt, Kyte (2002c) inferred that the original asteroid was a meteoritic basalt with $\sim 4 \mathrm{wt} \%$ metal. Another melt produced by this impact formed spherules that are only a trace component of the ejecta (Fig. 7, D and E; Margolis et al., 1991). The spherules are not vesicular and contain only $\sim 5 \mathrm{ng} / \mathrm{g} \mathrm{Ir}$, as opposed to $187 \mathrm{ng} / \mathrm{g}$ in the vesicular melt (Kyte, 2002c). Therefore these spherules must have formed under different conditions than the bulk of the ejecta, but the causes of these differences are unknown. It is conceivable that if ejecta from this impact is ever discovered at sites far removed from ground zero, it may be dominated by spheroidal rather than vesicular debris.

The highly vesicular characteristics of oceanic impact melts have probably hindered their discovery in sediments, because they may be confused with volcanic ash. One possible diagnostic criterion could be a very high density of very small vesicles that produce a rough surface texture (Fig. 7A). In polished section, vesicular melt from a chondritic source should contain abundant olivine, an interstitial glass, and an oxide phase, as in cosmic spherules (e.g., Brownlee, 1985). Qualitative energy dispersive analyses in an SEM would easily detect $\mathrm{Ni}$, an element unlikely to be from a terrestrial source.

\section{Isotopic tracers}

Three isotopic systems have been used successfully to trace meteoritic matter in sediments. Each system has proven useful in measuring different aspects of the accretion of extraterrestrial materials on Earth.

$R e-O s$ system. This system is based on the decay of ${ }^{187} \mathrm{Re}$ to ${ }^{187} \mathrm{Os}$ (half life, $t_{1 / 2}=45.6 \mathrm{~b}$.y.), and the differing geochemical behaviors of Re and Os (Faure, 1986). The potential of this isotopic system as a tracer of extraterrestrial matter was first recognized by Turekian (1982) at the first Snowbird Conference. While mantle rocks are expected to have an osmium isotopic composition, measured as ${ }^{187} \mathrm{Os} /{ }^{186} \mathrm{Os}$, similar to that in chondritic meteorites, crustal rocks should have very different values. This is because during melting in the upper mantle, $R e$ behaves as an incompatible element and has been enriched in derivative melts relative to $O s$, which is concentrated in residual mantle solids. Thus, crustal rocks have $\mathrm{Re} / \mathrm{Os}$ ratios much greater than those in the mantle or in chondrites, and the decay of the excess ${ }^{187} \operatorname{Re}$ has led to high levels of ${ }^{187} \mathrm{Os}$ in the crust. Turekian (1982) predicted that if K-T boundary sediments were enriched in extraterrestrial matter, they should have ${ }^{187} \mathrm{Os} /{ }^{186} \mathrm{Os}$ ratios near unity, the value in chondrites, whereas crustal rocks should have ${ }^{187} \mathrm{Os} /{ }^{186} \mathrm{Os}$ at least an order of magnitude higher. 


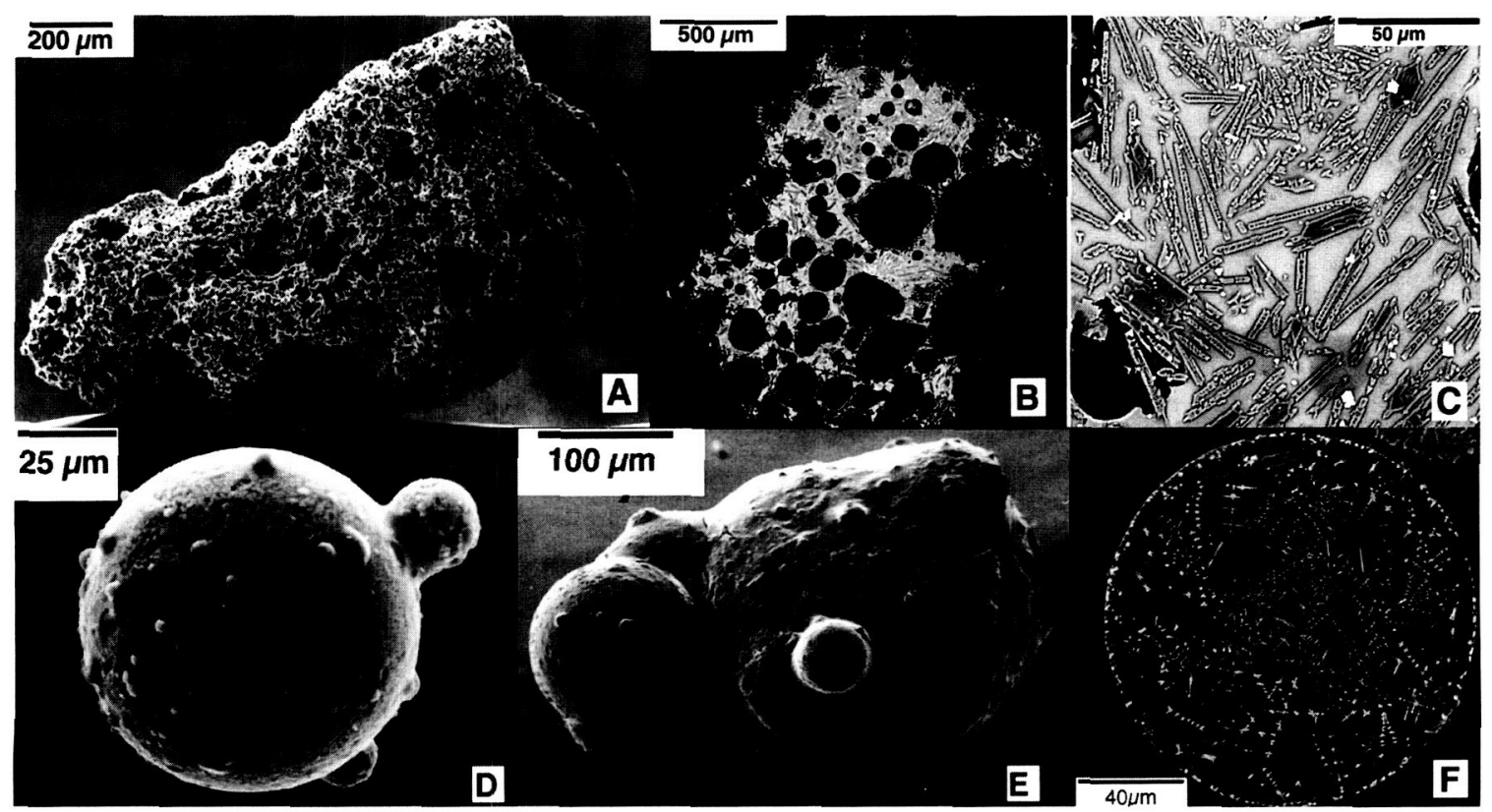

Figure 7. Images of melt materials from Eltanin asteroid oceanic impact. A: Secondary electron image of vesicular impact melt-rock particle. B: Backscatter electron image of polished section of vesicular impact melt-rock particle. C: Portion of B showing glass with olivine crystals. Small white grains are chromite. D: Secondary electron image of spherule from Eltanin impact. These spherules commonly have multiple small droplets attached to their surfaces. E: Secondary electron image of highly compound spherule from Eltanin impact. F: Backscatter electron impact of polished section of Eltanin impact spherule. Skeletal spinels (white) are imbedded in glass groundmass (gray). Black holes are probably from olivine that has dissolved.

Luck and Turekian (1983) confirmed this prediction when they found ${ }^{187} \mathrm{Os} /{ }^{186} \mathrm{Os}$ ratios of 1.3 and 1.6 in K-T boundary clays from the Raton basin, Colorado, and Stevns Klint, Denmark, respectively. In the same study they found that manganese nodules, which should reflect the seawater composition, had ${ }^{187} \mathrm{Os} /{ }^{186} \mathrm{Os}$ ratios ranging from $\sim 6$ to 8 . Although this was the first isotopic evidence to support the K-T boundary extinction hypothesis, it remained ambiguous because it left open the possibility that K-T boundary PGEs were from mantle sources, which should have Os isotopic abundances similar to those in chondritic meteorites. The discovery of enhanced Ir concentrations in aerosols from Kilauea, Hawaii (Zoller et al., 1983), provided an alternate potential source for the $\mathrm{Ir}$ and $\mathrm{Os}$, and lent considerable credence to a volcanic alternative to the K-T boundary impact model.

Osmium isotopes have also proven useful in estimating the long-term flux of extraterrestrial matter to the Earth (Esser and Turekian, 1988; Peucker-Ehrenbrink, 1996). Simple chemical methods, such as accumulation rates of Ir or Os in marine sediments (Barker and Anders, 1968; Kyte and Wasson, 1986), essentially provide an upper limit on the meteoritic flux, because some fraction of the PGEs in sediments is terrestrial. Os isotopes make it possible to model terrestrial contributions from crustal and mantle sources. The flux of $37000 \pm 13000 \mathrm{t} / \mathrm{yr}$ of extraterrestrial matter in Pacific sediments, based on Os isotopes (Peucker-Ehrenbrink, 1996), is probably the best estimate available to date. In addition to its application to the flux of meteoritic matter, the Os isotopic compositions of sediments and seawater have proven to be a useful measure of a number of terrestrial processes (e.g., Peucker-Ehrenbrink et al., 1995; Ravizza and Pyle, 1997).

Helium isotopes. Because of their high surface areas relative to their mass, interplanetary dust particles have high concentrations of solar-wind implanted He (Rajan et al., 1977), and thus ${ }^{3} \mathrm{He} /{ }^{4} \mathrm{He}$ ratios much higher than in any terrestrial materials (Nier and Schlutter, 1990). Much of this He survives atmospheric entry and is deposited in deep-sea sediments. Ozima et al. (1984) found an approximately inverse relationship between ${ }^{3} \mathrm{He}$ concentrations and the accumulation rate of Pacific surface sediments, a relationship that was attributed to the influx of interplanetary dust. Ozima et al. (1984) calculated an influx rate of only $2000 \mathrm{t} / \mathrm{yr}$, at least an order of magnitude lower than other influx estimates (e.g., Barker and Anders, 1968; Kyte and Wasson, 1986; Love and Brownlee, 1993; Peucker-Ehrenbrink, 1996). This is because the ${ }^{3} \mathrm{He}$ is most concentrated in the finest fractions of the interplanetary dust complex and is degassed from larger particles during atmospheric entry (e.g., Joswiak et al., 2000). Although the ${ }^{3} \mathrm{He}$ content of sediments is not a measure of the total influx of extraterrestrial matter, it is very useful because it is a tracer of the fine fraction of the interplanetary dust complex.

Farley (1995) showed that much of the ${ }^{3} \mathrm{He}$ flux is retained 
in pelagic clay sediments from the central north Pacific that are as old as $70 \mathrm{Ma}$. He also found an apparent peak both in the concentration and flux of ${ }^{3} \mathrm{He}$ in middle Cenozoic sediments. This peak in ${ }^{3} \mathrm{He}$ also corresponds to high concentrations of cosmic spherules and Ni-rich spinels (Kyte and Bostwick, 1985; Robin et al., 1999) in the same core (LL44-GPC3). Because of the low stratigraphic resolution of North Pacific clays, Farley et al. (1998) measured the ${ }^{3} \mathrm{He}$ flux in a high-resolution carbonate sequence from the Massignano quarry, Italy. They found a five-fold increase in the ${ }^{3} \mathrm{He}$ flux over an interval of $\sim 2$ m.y. in the late Eocene (Fig. 8). These sediments in Massignano also contain at least one Ir anomaly (and possibly two), shocked minerals, and $\mathrm{Ni}$-rich spinel that are related to impacts in the late Eocene (Montanari et al., 1993; Clymer et al., 1996; Pierrard et al., 1998). The two largest impact structures known in the Cenozoic, Popigai and Chesapeake Bay, are also roughly coincident with this time interval (Bottomley et al., 1997; Koeberl et al., 1996). Farley et al. (1998) concluded that the only possible source for this increase in ${ }^{3} \mathrm{He}$ flux was an increase in the interplanetary dust in the inner solar system. Because dust particles have a dynamic lifetime of only $\sim 10^{5}$ yr before they spiral into the Sun, they would need to be continuously replenished to produce an anomaly for 2 m.y. Farley et al. (1998) concluded that the only reasonable source was a comet shower, which could have a duration of about 3 m.y. (Hut et al., 1987). With this discovery, Farley et al. (1998) presented the first physical evidence that required a perturbation of the Oort Cloud of comets. This was not detected from major large-body impacts, but through tracers from fine-grained dust. Mukhopadhyay et al. (2001) measured ${ }^{3} \mathrm{He}$ in a high-resolution section of pelagic limestone from Gubbio, Italy, providing the first detailed profile of the accretion rate of interplanetary dust from the early Maastrichtian to the middle Eocene. Although there appear to be variations in the flux of dust by factors of two or more, they found no evidence of new comet showers, as had been identified in the late Eocene (Farley et al., 1998).

Chromium isotopes. Extraterrestrial material can contain two types of $\mathrm{Cr}$ isotopic anomalies. One of these is based on the decay of ${ }^{53} \mathrm{Mn}$ to ${ }^{53} \mathrm{Cr}\left(t_{1 / 2}=3.7\right.$ m.y. $)$. Although ${ }^{53} \mathrm{Mn}$ was present in the early solar system, it rapidly decayed to extinction. The decay products of ${ }^{53} \mathrm{Mn}$ were first discovered in refractory inclusions from the Allende meteorite, a CV-type carbonaceous chondrite (Birck and Allegre, 1985), and have now been identified in a variety of solar system objects (Lugmair and Shukolyukov, 1998; Birck and Allegre, 1988). These studies have shown that ${ }^{53} \mathrm{Mn}$ was heterogeneously distributed in the early solar system and that different types of meteorites can have distinct ${ }^{53} \mathrm{Cr} /{ }^{52} \mathrm{Cr}$ ratios (Lugmair and Shukolyukov, 1998; Shukolyukov and Lugmair, 1999). Because the Earth homogenized long after the ${ }^{53} \mathrm{Mn}$ decayed, all terrestrial rocks should have identical ${ }^{53} \mathrm{Cr} /{ }^{52} \mathrm{Cr}$ ratios. The isotopic variations in meteorites are measured as the deviations of the ${ }^{53} \mathrm{Cr} /{ }^{52} \mathrm{Cr}$ ratios from the standard terrestrial ${ }^{53} \mathrm{Cr} /{ }^{52} \mathrm{Cr}$ ratio and are usually expressed in $\varepsilon$ units ( $1 \varepsilon$ is 1 part in $10^{4}$, or $0.01 \%$ ). Thus, by definition, the standard terrestrial ${ }^{53} \mathrm{Cr} /{ }^{52} \mathrm{Cr}$ is $\equiv 0 \varepsilon$. The other type of $\mathrm{Cr}$ isotopic anomaly is an excess of ${ }^{54} \mathrm{Cr}$ known to occur in carbonaceous chondrites (Papanastassiou, 1986; Podosek et al., 1997).

High-precision measurements of ${ }^{53} \mathrm{Cr} /{ }^{52} \mathrm{Cr}$ ratios in ordinary chondrites, differentiated meteorites, and Martian meteorites (SNCs) show that all these extraterrestrial materials have an excess of ${ }^{53} \mathrm{Cr}$ relative to terrestrial rocks (Lugmair and Shukolyukov, 1998), and thus a positive value for $\varepsilon^{53} \mathrm{Cr}$ for all meteorites, except the carbonaceous chondrites (Fig. 9). The high-precision measurement of this ratio relies on a secondorder fractionation correction that is based on a normalization

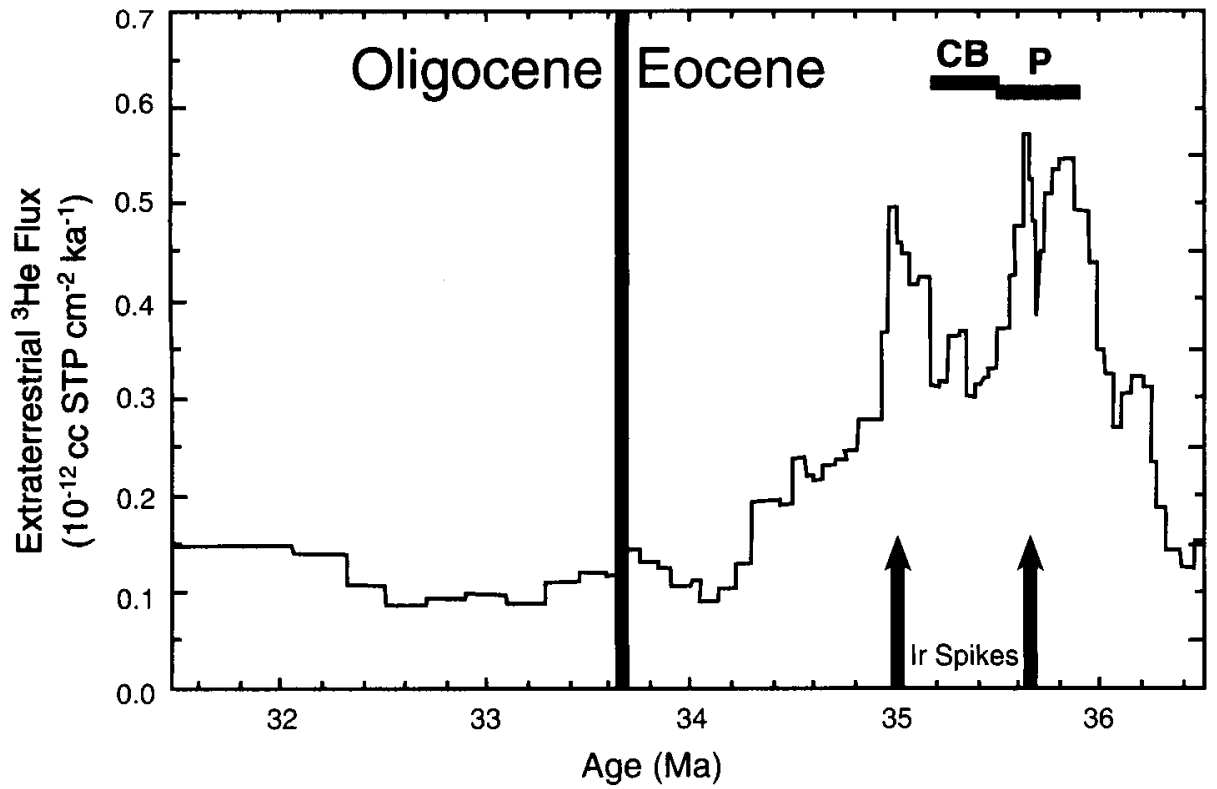

Figure 8. Peak in flux of ${ }^{3} \mathrm{He}$ is found in late Eocene sediments from Massignano, Italy. This is roughly coincident with at least one Ir anomaly, spherule deposits, and two large impact craters, Chesapeake Bay (CB) and Popigai (P). After Farley et al. (1998). 


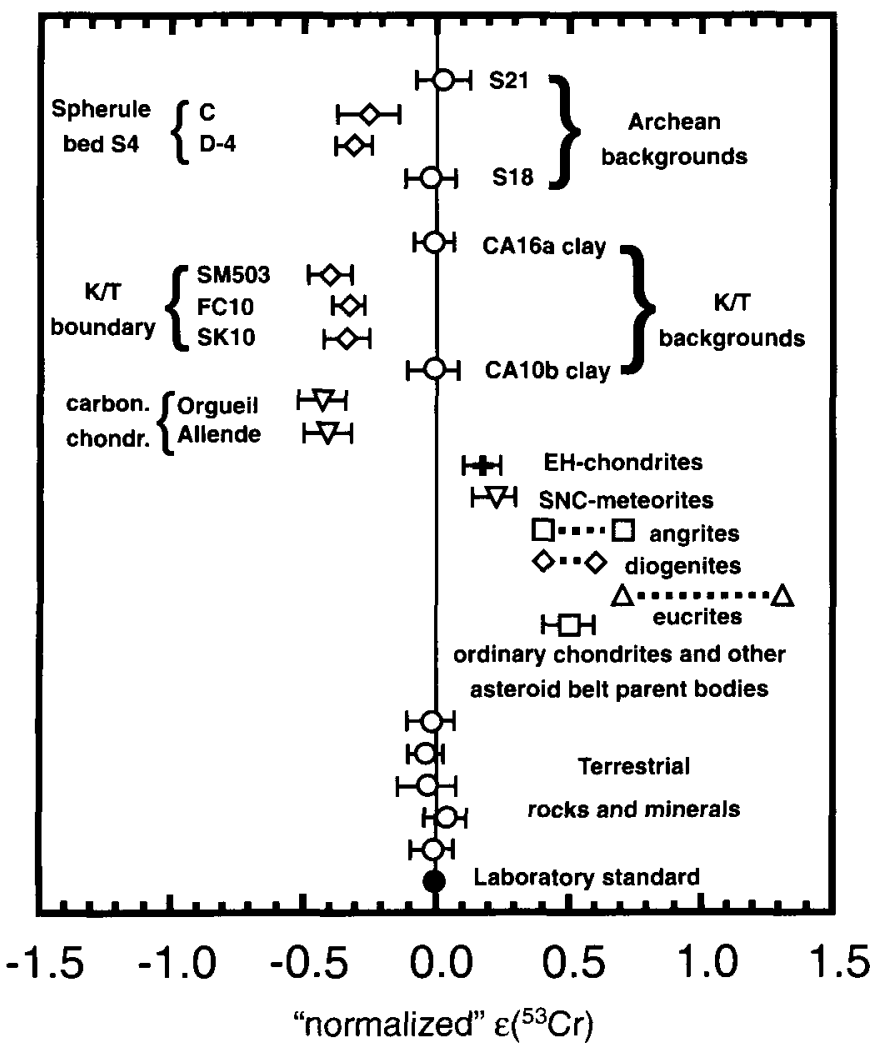

Figure 9. All terrestrial materials, including background sediments near impact deposits, have $\mathrm{Cr}$ isotopic compositions with $\varepsilon{ }^{53} \mathrm{Cr}=0$. Most meteorites have positive $\varepsilon^{53} \mathrm{Cr}$ values, reflecting excess of ${ }^{53} \mathrm{Cr}$. Carbonaceous chondrites have normalized $\varepsilon{ }^{53} \mathrm{Cr}$ that is negative, reflecting excess of both ${ }^{53} \mathrm{Cr}$ and ${ }^{54} \mathrm{Cr}$ relative to terrestrial samples. Samples from Cretaceous-Tertiary (K-T) boundary and Early Archean spherule bed have negative normalized $\varepsilon{ }^{53} \mathrm{Cr}$, indicating confirmed extraterrestrial component similar to that in carbonaceous chondrites. After Shukolyukov et al. (2000a).

to ${ }^{54} \mathrm{Cr}$. Therefore, when $\mathrm{Cr}$ isotopes are measured in carbonaceous chondrites, which have an excess of ${ }^{54} \mathrm{Cr}$, this fractionation correction results in a normalized $\varepsilon^{53} \mathrm{Cr}$ that has negative values relative to terrestrial rocks (Fig. 9). Thus, high precision $\mathrm{Cr}$ isotopic analyses can distinguish meteoritic materials from terrestrial rocks and carbonaceous chondrites from other meteorite groups (Shukolyukov et al., 2000a).

Shukolyukov and Lugmair (1998) applied this method to K-T boundary sediments from Caravaca, Spain, and Stevns Klint, Denmark. As expected, background sediments from Caravaca have $\varepsilon{ }^{53} \mathrm{Cr}$ values indistinguishable from the terrestrial value of zero. The K-T boundary clays, however, have normalized $\varepsilon{ }^{53} \mathrm{Cr}$ of $\sim-0.4$ and are indistinguishable from the carbonaceous chondrites Orgueil and Allende (Fig. 9). It took 18 years from the initial report of anomalous Ir in K-T boundary sediments, but this method provided the first unequivocal isotopic proof of an extraterrestrial component in the K-T boundary. In addition, this work showed that the K-T projectile had both anomalous ${ }^{53} \mathrm{Cr}$ and ${ }^{54} \mathrm{Cr}$ and was probably related to the carbonaceous chondrites, a result consistent with interpretations of relict textures in a fossil K-T meteorite (Kyte, 1998).

Chromium isotopic data have been obtained on Early Archean spherule bed S4 (Shukolyukov et al., 2000a), which also has a negative $\varepsilon{ }^{53} \mathrm{Cr}$ (Fig. 9). This deposit is now clearly identified as containing $\mathrm{Cr}$ from an extraterrestrial source such as a carbonaceous chondrite. Preliminary reports (Shukolyukov et al., 2000b) from another spherule bed (S3) indicate that it may have a similar source.

The $\mathrm{Cr}$ isotopic method has enormous potential as a tracer of extraterrestrial matter. The main limitation of this technique is that a significant fraction of the $\mathrm{Cr}$ in a sample (perhaps at least $30 \%$ ) must be meteoritic. Thus, $\mathrm{Cr}$ isotopes are not useful as a tracer of the background flux of extraterrestrial matter, but they are useful for ejecta deposits with high $\mathrm{Ir}$ and $\mathrm{Cr}$ concentrations. One intriguing possibility is that $\mathrm{Cr}$ isotopes might be able to identify ejecta from a projectile with low concentrations of Ir. For example, differentiated meteorites such as howardites, eucrites, and diogenites have Ir concentrations at levels typically $<1 \%$ of the concentration in chondrites (Mittlefehldt et al., 1998), but $\mathrm{Cr}$ concentrations 10-100 times higher than in typical sediments. Ejecta from the impact of a eucritic asteroid would be virtually undetectable using siderophile elements, but well within the range of possibility using $\mathrm{Cr}$ isotopic analyses.

\section{CONCLUSIONS}

Much has been learned in the past two decades about the accretion history of the Earth. The interplanetary dust complex is becoming very well characterized. The finest fraction of this, the stratospheric IDPs, are mostly derived from chondritic materials. IDPs that are most likely from asteroidal sources generally are compact and have hydrated minerals, whereas IDPs from cometary sources appear to mostly be porous anhydrous aggregates with GEMS. Cosmic spherule collections and associated micrometeorites from the coarse fraction of the dust complex have characteristics that are compatible with an origin mostly from asteroidal material similar to carbonaceous chondrite meteorites.

The long-term flux of interplanetary dust has been relatively constant for much of the past 70 m.y., except for a pulse in the late Eocene recorded by high concentrations of ${ }^{3} \mathrm{He}$ in marine sediments. This is coincident with one or more Ir anomalies, at least two spherule deposits, and two large impact structures. Because this pulse of dust persists for at least $2 \mathrm{~m} . \mathrm{y}$., this is believed to be the signature of a comet shower, triggered by a perturbation of the Oort Cloud of comets. Although it is well established that the Eocene-Oligocene transition was marked by high extinction rates (Raup and Sepkoski, 1984), and rapid climate change (e.g., Zachos et al., 1996), these phenomena have not been linked to this apparent comet shower by any strong physical data.

Deposits of the major impact event at the K-T boundary are now extremely well characterized. The fallout layer from 
the global ejecta probably contained $5 \%-10 \%$ chondritic material, and one carrier of this component is spinel-bearing spherules. Analyses of a small fossil meteorite, as well as the isotopic composition of $\mathrm{Cr}$ in K-T boundary sediments, point to a projectile similar to carbonaceous chondrites. Physical debris (i.e., Ni-rich spinels) in the global fallout is restricted to a single layer, and there is no strong evidence to support any hypothesis other than a single, geologically instantaneous accretionary event. This observation, in addition to the apparent lack of an increased flux of ${ }^{3} \mathrm{He}$ at the K-T boundary, are strong arguments against a comet shower at $65 \mathrm{Ma}$. That the K-T meteorite is more similar to compact, hydrated IDPs than to anhydrous porous IDPs is also reason to suspect an asteroidal, rather than a cometary source for the K-T projectile.

Very little is known about the meteoritic flux through the rest of the Phanerozoic. Exhaustive searches of a number of extinction horizons in sediments have failed to find conclusive evidence of an extraterrestrial component. At this time, the only great mass extinction that can be confidently linked to a major impact event is that at the K-T boundary. Considerably more work is needed in this area.

A number of potential impact deposits ranging in age from 0.6 to $3.4 \mathrm{Ga}$ have been identified in the Precambrian. Most spectacular among these are a number of thick spherule deposits in the Barberton Greenstone Belt, South Africa. Chromium isotopes have conclusively shown that at least one of these contains $\sim 20 \%$ meteoritic material with an isotopic composition similar to that of $\mathrm{CV}$ chondrites. If other beds can be proven to contain high concentrations of extraterrestrial matter, they may indicate an extensive record of megaimpacts, possibly by projectiles considerably larger than the K-T impactor.

\section{ACKNOWLEDGMENTS}

I thank I. McDonald and B. Schmitz for helpful reviews. This work was supported by NASA grant NAG5-9411.

\section{REFERENCES CITED}

Alekseev, A.S., Barsukova, L.D., Kolesov, G.M., Nazarov, M.A., and Grigoryan, A.G., 1983, The Permian-Triassic boundary event: Geochemical investigation of the Transcaucasia section [abs.]: Lunar and Planetary Science, v. 14, p. $3-4$.

Alvarez, L.W., Alvarez, W., Asaro, F., and Michel, H.V., 1980, Extraterrestrial cause for the Cretaceous-Tertiary extinction: Science, v. 208, p. 10951108.

Artemieva, N.A., and Shuvalov, V.V., 2002, Shock metamorphism on the ocean floor (numerical simulations): Deep Sea Research II, v. 49, p. 959-968.

Asaro, F., Alvarez, L.W., Alvarez, W., and Michel, H.V., 1982, Geochemical anomalies near the Eocene/Oligocene and Permian/Triassic boundaries: Geological Society of America Special Paper 190, p. 517-528.

Barker, J.L., and Anders, E., 1968, Accretion rate of cosmic matter from iridium and osmium contents of deep-sea sediments: Geochimica et Cosmochimica Acta, v. 32 , p. 627-645.

Becker, L., 2000, Fullerenes, noble gases and the flux of extraterrestrial debris to the surface of the earth over geologic time: First Astrobiology Conference, Mountain View, California, Abstracts, p. 30.

Becker, L., Bada, J.L., Winans, R.E., Hunt, J.E., Bunch, T.E., and French, B.M., 1994, Fullerenes in the 1.85-billion-year-old Sudbury impact structure: Science, v. 265 , p. $642-644$.

Becker, L., Poreda, R.J., and Bada, J.L., 1996, Extraterrestrial helium trapped in fullerenes in the Sudbury impact structure: Science, v. 272 , p. 249 252.

Bell, J.F., Davis, D.R., Hartman, W.K., and Gaffey, M.J., 1989, Asteroids: The big picture, in Binzel, R.P., Gehrels, R., and Matthews, M.S., eds., Asteroids II: Tucson, University of Arizona Press, p. 921-945.

Birck, J.-L., and Allègre, C.J., 1985, Evidence for the presence of ${ }^{53} \mathrm{Mn}$ in the early solar system: Geophysical Research Letters, v. 12, p. 745-748.

Birck, J.-L., and Allègre, C.J., 1988, Manganese-chromium isotope systematics and development of the early solar system: Nature, v. 331, p. 579-584.

Bohor, B.F., Ford, E.E., and Ganapathy, R., 1986, Magnesioferrite from the Cretaceous-Tertiary boundary, Caravaca, Spain: Earth and Planetary Science Letters, v. 81, p. 57-66.

Bohor, B.F., and Glass, B.P., 1995, Origin and diagenesis of K/T impact spherules-from Haiti to Wyoming and beyond: Meteoritics, v. 30, p. 182198.

Bonner, F.T., and Laurenco, A.S., 1965, Nickel content in Pacific Ocean cores: Nature, v. 207, p. 933-935.

Bottomley, R., Grieve, R.A.F., York, D., and Masaitis, V., 1997, The age of the Popigai impact event and its relationship to events at the Eocene/Oligocene boundary: Nature, v. 388, p. 365-368.

Bradley, J.P., Brownlee, D.E., 1991, An interplanetary dust particle linked directly to type-CM meteorites and an asteroidal origin: Science, v. 251, p. $549-552$.

Bradley, J.P., Keller, L.P., Snow, T.P., Hanner, M.S., Flynn, G.J., Gezo, J.C., Clemett, S.J., Brownlee, D.E., and Bowey, J.E., 1999, An infrared spectral match between GEMS and interstellar grains: Science, v. 285, p. 17161718.

Brownlee, D.E., 1985, Cosmic dust: Collection and research: Annual Review of Earth and Planetary Sciences, v. 13, p. 147-173.

Brownlee, D.E., Pilachowski, L.B., and Hodge, P.W., 1979, Meteorite mining on the ocean floor [abs.]: Lunar and Planetary Science, v. 10, p. 157-158.

Brownlee, D.E., Joswiak, D., and Bradley, J.P., 1997a, Vesicular carbon in strongly heated IDPs [abs.]: Lunar and Planetary Science, v. 27, Abstract $\# 1585$, CD-ROM.

Brownlee, D.E., Bates, B., and Schramm, L., 1997b, The elemental composition of stony cosmic spherules: Meteoritics and Planetary Science, v. 32, p. $157-175$.

Byerly, G.R., and Lowe, D.R., 1994, Spinel from Archean impact spherules: Geochimica et Cosmochimica Acta, v. 58, p. 3469-3486.

Castaing, R., and Fredriksson, K., 1958, Analyses of cosmic spherules with and X-ray microanalyzer: Geochimica et Cosmochimica Acta, v. 14, p. $114-117$.

Chou, C.-L., 1978, Fractionation of siderophiles elements in the earth's upper mantle: Proceedings of the 9th Lunar and Planetary Science Conference, p. 219-230.

Chyba, C.F., Thomas, P.J., and Zahnle, K.J., 1993, The 1908 Tunguska explosion: Atmospheric disruption of a stony asteroid: Nature, v. 361, p. $40-44$.

Claeys, P., and Casier, J.-G., 1994, Microtektite-like impact glass associated with the Frasnian-Famennian boundary mass extinction: Earth and Planetary Science Letters, v. 122, p. 303-315.

Claeys, P., Kyte, F.T., Herbosh, A., and Casier, J.-G., 1996, Geochemistry of the Frasnian Famennian boundary: Mass extinctions, anoxic oceans, and microtektite layer, but not much iridium?, in Ryder, G., Fatovsky, D., and Gartner, S., eds., The Cretaceous-Tertiary boundary and other catastrophes in Earth history: Geological Society of America Special Paper 307. p. 491-504.

Clark, D.L., Wang, C., Orth, C.J., and Gilmore, J.S., 1986, Conodont survival 
and low iridium abundances across the Permian-Triassic boundary in south China: Science, v. 233, p. 984-986.

Clymer, A.K., Bice, D.M., and Montanari, A., 1996, Shocked quartz from the late Eocene: Impact evidence from Massignano, Italy: Geology, v. 24, p. 483-486.

Colodner, D.C., Boyle, E.A., Edmond, J.M., and Thomson, J., 1992, Postdepositional mobility of platinum, iridium, and rhenium in marine sediments: Nature, v. 358 , p. $402-404$.

Crocket, J.H., and Kuo, H.Y., 1979, Sources for gold, palladium, and iridium in deep-sea sediments: Geochimica et Cosmochimica Acta, v. 43, p. 831842.

Czajkowski, J., 1987, Cosmo and geochemistry of the Jurassic hardgrounds [Ph.D. thesis]: San Diego, University of California, $418 \mathrm{p}$.

Davis, M., Hut, P., and Muller, R.A., 1984, Extinction of species by periodic comet showers: Nature, v. 308, p. 715-717.

Dodd, R.T., 1989, Unique find from Antarctica: Nature, v. 338, p. 296-297.

Ebel, D.S., and Grossman, L., 1999, Condensation in a model Chicxulub fireball [abs.]: Lunar and Planetary Science, v. 30, Abstract \#1906, CD-ROM.

Engrand, C., and Maurette, M., 1998, Carbonaceous micrometeorites from Antarctica: Meteoritics and Planetary Science, v. 33, p. 565-580.

Esser, B.K., and Turekian, K.K., 1988, Accretion rate of extraterrestrial particles determined from osmium isotope systematics of Pacific pelagic clay and manganese nodules: Geochimica et Cosmochimica Acta, v. 52, p. 1383-1388.

Evans, N.J., Gregoire, D.C., Goodfellow, W.D., McInnes, B.I., Miles, N., and Veizer, J., 1993, Ru/Ir ratios at the Cretacous-Tertiary boundary: Implications for PGE source and fractionation within the ejecta cloud: Geochimica et Cosmochimica Acta, v. 57, p. 3149-3158.

Farley, K.A., 1995, Cenozoic variations in the flux of interplanetary dust recorded by $\mathrm{He}-3$ in a deep-sea sediment: Nature, v. 376, p. 153-156.

Farley, K.A., Montanari, A., Shoemaker, E.M., and Shoemaker, C.S., 1998, Geochemical evidence for a comet shower in the Late Eocene: Science, v. 280, p. $1250-1253$.

Faure, G., 1986, Principles of isotope geology (second edition): New York, John Wiley \& Sons, $589 \mathrm{p}$.

Ganapathy, R., 1980, A major meteorite impact on the earth 65 million years ago: Evidence from the Cretacous-Tertiary boundary clay: Science, v. 209 , p. 921-923.

Ganapathy, R., 1982, Evidence for a major meteorite impact on the earth 34 million years ago: Implications for Eocene extinctions: Science, v. 216, p. 885-886.

Ganapathy, R., Brownlee, D.E., and Hodge, P.W., 1978, silicate spherules from deep-sea sediments: Confirmation of extraterrestrial origin: Science, $v$. 201, p. 1119-1121.

Gayraud, J., Robin, E., Rocchia, R., and Froget, L., 1996, Formation conditions of oxidized $\mathrm{Ni}$-rich spinel and their relevance to the $\mathrm{K} / \mathrm{T}$ boundary event: Geological Society of America Special Paper 307, p. 425-443.

Gersonde, R., Kyte, F.T., Bleil, U., Diekmann, B., Flores, J.A., Gohl, K., Grahl, G., Hagen, R., Kuhn, G., Sierro, F.J., Völker, D., Abelmann, A., and Bostwick, J.A., 1997, Geological record and reconstruction of the late Pliocene impact of the Eltanin asteroid in the Southern Ocean: Nature, v. 390 , p. $357-363$.

Gilmore, J.S., Knight, J.D., Orth, C.J., Pillmore, C.L., and Tschudy, R.H., 1984, Trace element patterns at a non-marine Cretaceous-Tertiary boundary: Nature, v. 307, p. 224-228.

Glass, B.P., and Burns, C.A., 1987, Late Eocene crystal-bearing spherules: Two layers or one?: Meteoritics, v. 22, p. 265-279.

Glass, B.P., and Koeberl, C., 1999, Ocean Drilling Project Hole 689B spherules and upper Eocene microtektite and clinopyroxene-bearing spherule strewn fields: Meteoritics and Planetary Science, v. 34, p. 197-208.

Glass, B.P., Burns, C.A., Crosbie, J.R., and DuBois, D.L., 1985, Late Eocene North American microtektites and clinopyroxene-bearing spherules: Journal of Geophysical Research, v. 90, p. D175-D196.

Gostin, V.A., Haines, P.W., Jenkins, R.J.F., Compston, W., and Williams, I.S., 1986, Impact ejecta horizon within late Precambrian shales, Adelaide geosyncline, South Australia: Science, v. 233, p. 198-200.
Gostin, V.A., Keays, R.R., and Wallace, M.W., 1989, Iridium anomaly from the Acraman impact ejecta horizon: Impacts can produce sedimentary iridum peaks: Nature, v. 340, p. 542-544.

Herzog, G.F., Xue, S., Hall, G.S., Nyquist, L.E., Shih, C.Y., Wiesmann, H., Brownlee, D.E., 1999, Isotopic and elemental composition of iron, nickel, and chromium in type I deep-sea spherules: Implications for origin and composition of the parent micrometeoroids: Geochimica et Cosmochimica Acta, v. 63, p. 1443-1457.

Heymann, D., Chibante, L.P.F., Brooks, R.R., Wolbach, W.S., and Smalley, R.E., 1994, Fullerenes in the Cretaceous-Tertiary boundary layer: Science, v. 265, p. 645-647.

Hut, P., Alvarez, W., Elder, W.P., Hansen, T., Kauffman, E.G., Keller, G., Shoemaker, E.M., and Weissman, P.R., 1987, Comet showers as a cause of mass extinctions: Nature, v. 329, p. 118-126.

Jehanno, C., Boclet, D., Bonte, Ph., Castellarin, A., and Rocchia, R., 1988, Identification of two populations of extraterrestrial particles in a Jurassic hardground of the southern Alps: Proceedings of the $18^{\text {th }}$ Lunar and Planetary Science Conference, p. 625-630.

Jessberger, E.K., and Kissel, J., 1989, The compositions of comets, in Atreya, S.K., Pollack, J.B., and Matthews, M.S., eds., Origin and evolution of planetary and satellite atmospheres: Tuscon, Univiversity of Arizona Press, p. 167-191.

Joswiak, D.J., Brownlee, D.E., Pepin, R.O., and Schlutter, D.J., 2000, Characteristics of asteroidal and cometary IDPs obtained from stratospheric collectors: Summary of measured He release temperatures, velocities and descriptive [abs.]: Lunar and Planetary Science, v. 31, Abstract \#1500, CD-ROM.

Kettrup, D., Deutsch, A., Pihlaja, P., and Pesonen, L.J., 2000, Fossil micrometeorites from Finland: Basic features, scientific potential, and characteristics of the Mesoproterozoic host rocks, in Gilmour, I., and Koeberl, C., eds., Impacts and the early earth: Heidelberg, Germany, SpringerVerlag, Lecture Notes in Earth Sciences, v. 92, p. 215-227.

Klöck, W., Thomas, K.L., McKay, D.S., and Palme, H., 1989, Unusual olivine and pyroxene composition in interplanetary dust and unequilibrated ordinary chondrites: Nature, v. 339, p. 126-128.

Koeberl, C., 1998, Identification of meteoritic components in impactites, in Grady, M.M., Hutchison, R., McCall, G.H., and Rothery, D.A., eds., Meteorites: Flux with time and impact effects: Geological Society [London] Special Publication 140, p. 133-153.

Koeberl, C., and Reimold, W.U., 1995, Early Archean spherule beds in the Barberton Mountain Land, South Aftica: No evidence for impact origin: Precambrian Research, v. 74, 1-33.

Koeberl, C., Reimold, W.U., and Boer, R.H., 1993, Geochemistry and mineralogy of early Archean spherule beds, Barberton Mountain Land, South Aftica: Evidence for origin by impact doubtful: Earth and Planetary Science Letters, v. 119 , p. $441-452$.

Koeberl, C., Poag, C.W., Reimold, W.U., and Brandt, D., 1996, Impact origin of the Chesapeake Bay structure and the source of the North American tektites: Science, v. 271, p. 1263-1266.

Kyte, F.T., 1988, The extraterrestrial component in marine sediments: Paleoceanography, v. 3. p. 235-247.

Kyte, F.T., 1998, A meteorite from the Cretaceous-Tertiary boundary: Nature, v. 396, p. $237-239$.

Kyte, F.T., 2002a, Iridium concentrations and abundances of meteoritic ejecta from the Eltanin impact in sediment cores from Polarstern expedition ANT XII/4: Deep Sea Research II, v. 49, p. 1049-1061.

Kyte, F.T., 2002b, Unmelted meteoritic debris collected from Eltanin Ejecta in Polarstern Cores from Expedition ANT XII/4: Deep Sea Research II, v. 49 , p. $1063-1071$.

Kyte, F.T., 2002c, Composition of Impact Melt Debris from the Eltanin Impact Strewn Field, Bellingshausen Sea: Deep Sea Research II, v. 49, p. 10291047.

Kyte, F.T., and Bostwick, J.A., 1995, Magnesioferrite spinel in CretaceousTertiary boundary sediments of the Pacific basin: Hot, early condensates of the Chicxulub impact?: Earth and Planetary Science Letters, v. 132, p. 113-127. 
Kyte, F.T., and Brownlee, D.E., 1985, Unmelted meteoritic debris in the Late Pliocene Ir anomaly: Evidence for the impact of a nonchondritic asteroid: Geochimica et Cosmochimica Acta, v. 49, p. 1095-1108.

Kyte, F.T., and Smit, J., 1986, Regional variations in spinel compositions: An important key to the Cretaceous-Tertiary event: Geology, v. 14, p. 485487.

Kyte, F.T., and Wasson, J.T., 1986, Accretion rate of extraterrestrial matter: Iridium deposited 33 to 67 million years ago: Science, v. 232, p. 12251229.

Kyte, F.T., Heath, G.R., Leinen, M., and Zhou, L., 1993, Cenozoic sedimentation history of the central North Pacific: Inferences from the elemental geochemistry of core LL44-GPC3: Geochimica et Cosmochimica Acta, v. 57 , p. $1719-1740$.

Kyte, F.T., Zhou, Z., and Wasson, J.T., 1980, Siderophile-enriched sediments from the Cretaceous-Tertiary boundary: Nature, v. 288, p. 651-656.

Kyte, F.T., Zhou, Z., and Wasson, J.T., 1981, High noble metal concentrations in a late Pliocene sediment: Nature, v. 292, p. 417-420.

Kyte, F.T., Smit, J., and Wasson, J.T., 1985. Siderophile interelement variations in the Cretaceous-Tertiary boundary sediments from Caravaca, Spain: Earth and Planetary Science Letters, v. 73, p. 183-195.

Kyte, F.T., Zhou, L., and Wasson J.T., 1988, New evidence on the size and possible effects of a late Pliocene oceanic impact: Science, v. 241, p. 63-65.

Kyte, F.T., Zhou, L., and Lowe D.R., 1992, Noble metal abundances in an early Archean impact deposit: Geochimica et Cosmochimica Acta, v. 56, p. 1365-1372.

Love, S.G., and Brownlee, D.E., 1993, A direct measurement of the terrestrial mass accretion rate of cosmic dust: Science, v. 262, p. 550-553.

Lowe, D.R., Byerly, G.R., Asaro, F., and Kyte, F.T., 1989, Geological and geochemical evidence for a record of 3,400 Ma-old terrestrial meteorite impacts: Science, v. 245 , p. $959-962$.

Luck, J.M., and Turekian, K.K., 1983, Osmium-187/Osmium-186 in manganese nodules and the Cretaceous-Tertiary boundary: Science, v. 222, p. 613-615.

Lugmair, G.W., and Shukolyukov, A., 1998, Early solar system timescales according to ${ }^{53} \mathrm{Mn}-{ }^{53} \mathrm{Cr}$ systematics: Geochimica et Cosmochimica Acta, v. 62, p. 2863-2886.

Margolis, S.V., Claeys, P., and Kyte, F.T., 1991, Microtektites, microkrystites and spinels from a Late Pliocene asteroid impact in the Southern Ocean: Science, v. 251, p. 1594-1597.

Marvin, U.B., and Einaudi, M.T., 1967, Black, magnetic spherules from Pleistocene and recent beach sands: Geochimica et Cosmochimica Acta, v. 31, p. $1871-1884$

Maurette, M., Hammer, C., Brownlee, D.E., Reeh, N., and Thomsen, H.H., 1986, Placers of cosmic dust in the blue ice lakes of Greenland: Science, v. 233 , p. $869-872$.

Mc Ghee, G.R., Orth, C.J., Gilmore, J.S., and Olsen, E.J., 1984, No geochemical evidence for an asteroidal impact at Late Devonian mass extinction horizon: Nature, v. 308, p. 629-631.

Mittlefehldt, D.W., McCoy, T.J., Goodrich, C.A., and Kracher, A., 1998, Nonchondritic meteorites from asteroidal bodies, in Papike, J.J., ed., Planetary materials: Reviews in Mineralogy, v. 36, p. 4-1-4-195.

Montanari, A., Hay, R.L., Alvarez, W., Asaro, F., Michel, H.V., Alvarez, L.W., and Smit, J., 1983, Spheroids at the Cretaceous-Tertiary boundary are altered impact droplets of basaltic composition: Geology, v. 11, p. 668671.

Montanari, A., Asaro, F., Michel, H.V., and Kennett, J.P., 1993, Iridium anomalies of late Eocene age at Massignano (Italy) and ODP Site 689B (Maude Rise, Antarctic): Palaios, v. 8, p. 420-437.

Mukhopadhyay, S., Farley, K.A., and Montanari, A., 2001, A 35 Myr record of helium in pelagic limestones from Italy: Implications for interplanetary dust accretion from the early Maastrichtian to the middle Eocene: Geochimica et Cosmochimica Acta, v. 65, p. 653-669.

Mukhopadhyay, S., Farley, K.A., Montanari, A., and Ahrens, T.J., 1998, Extraterrestrial ${ }^{3} \mathrm{He}$ in the sedimentary record [abs.]: Lunar and Planetary Science, v. 29, Abstract \#1535, CD-ROM.
Murray, J., and Renard, A.F., 1883, On the microscopic characters of volcanic ashes and cosmic dust, and their distribution in deep-sea deposits: Proceedings of the Royal Society of Edinburgh, v. 12, p. 474-495.

Murray, J., and Renard, A.F., 1891, Deep sea deposits, in Report on the scientific results of the H.M.S. Challenger during the years 1873-1876 [reprinted 1965]: New York, Johnson Reprint Corporation, 327 p.

Mutch, T.A., 1966, Abundances of magnetic spherules in Silurian and Permian salt samples: Earth and Planetary Science Letters, v. 1, p. 325-329.

Nier, A.O., and Schlutter, D.J., 1990, Helium and neon isotopes in stratospheric particles: Meteoritics, v. 25, p. 263-267.

Nishiizumi, K., 1983, Measurement of ${ }^{53} \mathrm{Mn}$ in deep sea iron and stony spherules: Earth and Planetary Science Letters, v. 63, p. 223-228.

Orth, C.I., Gilmore, J.S., and Knight, J.D., 1985, A search for evidence of large body Earth impacts associated with biological crisis zones in the fossil record [abs.]: Lunar and Planetary Science, v. 16, p. 631-632.

Orth, C.J., Attrep, M., Jr., Mao, X.Y., Kauffman, E.G., Diner, R., and Elder, W.P., 1988, Iridium abundance maxima in the upper Cenomanian extinction interval: Geophysical Research Letters, v. 15, p. 346-349.

Ozima, M., Takayanagi, M., Zashu, S., and Amari, S., 1984, High ${ }^{3} \mathrm{He}^{14} \mathrm{He}$ ratio in ocean sediments: Nature, v. 311, p. 448-450.

Palme, H., Janssens, M., Takahashi, H., Anders, E., and Hertogen, J., 1978, Meteoritic material at five large impact craters: Geochimica et Cosmochimica Acta, v. 42, p. 313-323.

Papanastassiou, D.A., 1986, Chromium isotopic anomalies in the Allende meteorite: Astrophysical Journal, v. 308, p. L27-L30.

Pettersson, H., and Fredriksson, K., 1958, Magnetic spherules in deep-sea deposits: Pacific Science, v. 12, p. 71-81.

Pettersson, H., and Rotschi, H., 1950, Nickel content of deep-sea deposits: Nature, v. 166 , p. $308-310$.

Peucker-Ehrenbrink, B., 1996, Accretion of extraterrestrial matter during the last 80 million years and its effect on the marine osmium isotope record: Geochimica et Cosmochimica Acta, v. 60, p. 3187-3196.

Peucker-Ehrenbrink, B., Ravizza, G., and Hofmann, A.W., 1995, The marine ${ }^{187} \mathrm{Os} /{ }^{186} \mathrm{Os}$ record of the past 80 million years: Earth and Planetary Science Letters, v. 130, p. 155-167.

Pierrard, O., Robin, E., Rocchia, R., and Montanari, A., 1998, Extraterrestrial $\mathrm{Ni}$-rich spinel in upper Eocene sediments from Massignano, Italy: Geology, v. 26, p. 307-310.

Podosek, F.A., Ott, U., Brannon, J.C., Neal, C.R., Bernatowicz, T.J., Swan, P., and Mahan, S.E., 1997, Thoroughly anomalous chromium in Orgueil: Meteoritics and Planetary Science, v. 32, p. 617-627.

Rajan, R.S., Brownlee, D.E., Tomandl, D., Hodge, P.W., Farrar, H., and Britten, R.A., 1977, Detection of ${ }^{4} \mathrm{He}$ in stratospheric particles gives evidence of extraterrestrial origin: Nature, v. 267, p. 133-134.

Rampino, M.R., and Stothers, R.B., 1984, Terrestrial mass extinctions, cometary impacts and the sun's motion perpendicular to the galactic plane: Nature, v. 308, p. 709-712.

Raup, D.M., and Sepkoski, J.J., 1984, Periodicity of extinctions in the geologic past: Proceedings of the National Academy of Science, USA, v. 81, p. 801-805.

Ravizza, G., and Pyle, D., 1997, PGE and Os isotopic analyses of single sample aliquots with NiS fire assay preconcentration: Chemical Geology, v. 141, p. 251-268.

Retallack, G.J., Seyedolali, A., Krull, E.S., Holser, W.T., Ambers, C.P., and Kyte, F.T., 1998, Search for evidence of impact at the Permian-Triassic boundary in Antarctica and Australia: Geology, v. 26, p. 979-982.

Robin, E., 1988, Des poussieres cosmiques dans les cryconites du Greenland: Nature, origine et applications [Ph.D. thesis]: Paris, University d'Orsay, $131 \mathrm{p}$.

Robin, E., Boclet, D., Bonte, Ph., Froget, L., Jehanno, C., and Rocchia, R., 1991, The stratigraphic distribution of $\mathrm{Ni}$-rich spinels in CretaceousTertiary boundary rocks at El Kef, (Tunisia), Caravaca (Spain) and Hole 761C (Leg 122): Earth and Planetary Science Letters, v. 107, p. 715-721.

Robin, E., Bonte, Ph., Froget, L., Jehanno, C., and Rocchia, R., 1992, Formation of spinels in cosmic objects during atmospheric entry: A clue to 
the Cretaceous-Tertiary boundary event: Earth and Planetary Science Letters, v. 108 , p. $181-190$.

Robin, E., Froget, L., Jéhanno, C., and Rocchia, R., 1993, Evidence for a K/T impact event in the Pacific Ocean: Nature, v. 363, p. 615-617

Robin, E., Pierrard, O., Lefevre, I., and Rocchia, R., 1999, A search for extraterrestrial spinel in pelagic sediments from the central North Pacific [abs.]: Geological Society of America Abstracts with Programs, v. 31, no. 7, p. A63.

Rocchia, R., Robin, E., Froget, L., and Gayraud, J., 1996, Stratigraphic distribution of extraterrestrial markers at the Cretaceous-Tertiary boundary in the Gulf of Mexico area: Implications for the temporal complexity of the event, in Ryder, G., Fatovsky, D., and Gartner, S., eds., The CretaceousTertiary boundary and other catastrophes in Earth history: Geological Society of America Special Paper 307, p. 279-286.

Sanfilippo, A., Riedel, W.R., Glass, B.P., and Kyte, F.T., 1985, Late Eocene microtektites and radiolarian extinctions on Barbados: Nature, v. 314, p. 613-615.

Schmidt, G., Zhou, L., and Wasson, J.T., 1993, Iridium anomaly associated with the Australian tektite-producing impact: Masses of the impactor and of the Australasian tektites: Geochimica et Cosmochimica Acta, v. 57, p. $4851-4859$

Schmitz, B., 1988, Origin of microlayering in worldwide distributed Ir-rich marine Cretaceous/Tertiary boundary clays: Geology, v. 16, p. 10681072 .

Schmitz, B., Lindstrom, M., Asaro, F., and Tassinari, M., 1996, Geochemistry of meteorite-rich marine limestone strata and fossil meteorites from the lower Ordovician at Kinnekulle, Sweden: Earth and Planetary Science Letters, v. 145, p. 31-48.

Shearer, C.K., Papike, J.J., and Rietmeijer, F.J.M., 1998, The planetary sample suite and environments of origin, in Papike, J.J., ed., Planetary materials: Reviews in Mineralogy, v. 36, p. 1-1-1-28.

Shukolyukov, A., and Lugmair, G.W., 1998, Isotopic evidence for the Cretaceous-Tertiary impactor and its type: Science, v. 282, p. 927-929.

Shukolyukov, A., and Lugmair, G.W., 1999, The ${ }^{53} \mathrm{Mn}^{53} \mathrm{Cr}$ isotope systematics of the enstatite chondrites [abs.]: Lunar and Planetary Science, v. 30, Abstract \#1093, CD-ROM.

Shukolyukov, A., Kyte, F.T., Lugmair, G.W., Lowe, D.R., and Byerly, G.R., 2000a, The oldest impact deposits on Earth: First confirmation of an extraterrestrial component, in Gilmour, I., and Koeberl, C., eds., Impacts and the early earth: Heidelberg, Germany, Springer-Verlag, Lecture Notes in Earth Sciences, v. 92, p. 99-116.

Shukolyukov, A., Kyte, F.T., Lugmair, G.W., Lowe, D.R., and Byerly, G.R., 2000b, Early Archean spherule beds: Confirmation of impact origin: Meteoritics and Planetary Science, Abstracts, v. 35, p. A146-A147.

Simonson, B.M., and Harnik, P., 2000, Have distal impact ejecta changed through geologic time?: Geology, v. 28, p. 975-978.

Simonson, B.M., Davies, D. Wallace, M., Reeves, S., and Hassler, S.W., 1998 Iridium anomaly but no shocked quartz from late Archean microkrystite layer: Oceanic impact ejecta?: Geology, v. 26, p. 195-198

Simonson, B.M., Koeberl, C., McDonald, I., and Reimold, W.U., 2000, Geochemical evidence for an impact origin for a Late Archean spherule layer, Transvaal Supergroup, South Africa: Geology, v. 28, p. 1103-1106.

Smit, J., 1999, The global stratigraphy of the Cretaceous-Tertiary boundary impact ejecta: Annual Review of Earth and Planetary Sciences, v. 27, p. $75-113$

Smit, J., Alvarez, W., Montanari, A., Swinburne, N., van Kempen, T.M., Klaver, G.T., and Lustenhouwer, W.J., 1992, "Tektites" and microkrystites at the Cretaceous Tertiary boundary: Two strewn fields, one crater? Proceedings of Lunar and Planetary Science, v. 22, p. 87-100.

Smit, J., and Hertogen, J., 1980, An extra-terrestrial event at the CretaceousTertiary boundary: Nature, v. 285, p. 198-200.

Smit, J., and Kyte, F.T., 1984, Siderophile-rich magnetic spheroids from the Cretaceous-Tertiary boundary in Umbria, Italy: Nature, v. 310, p. 403405 .
Taylor, S., Brownlee, D.E., 1991, Cosmic spherules in the cosmic record: Meteoritics, v. 26, p. 203-211.

Taylor, S., Lever, J.H., and Harvey, R.P., 2000, Numbers, types and compositions of an unbiased collection of cosmic spherules: Meteoritics and Planetary Science, v. 35, p. 651-666.

Thorslund, P., and Wickman, F.E., 1981, Middle Ordovician chondrite in fossiliferous limestone from Brunflo, central Sweden: Nature, v. 289, p. 285 286

Thorslund, P., Wickman, F.E., and Nystrom, J.A., 1984, The Ordovician chondrite from Brunflo, central Sweden. 1. General description and primary minerals: Lithos, v. 17 , p. $87-100$

Tredoux, M., DeWitt, M.J., Hart, R.J., Lindsay, N.M., Verhagen, B., and Sellschop, J.P.F., 1989, Chemostratigraphy across the Cretaceous-Tertiary boundary and a critical assessment of the iridium anomaly: Journal of Geology, v. 97, p. 585-605.

Turekian, K.K., 1982, Potential of ${ }^{187} \mathrm{Os} /{ }^{186} \mathrm{Os}$ as a cosmic versus terrestrial indicator in high iridium layers of sedimentary strata, in Silver, L.T., and Schultz, P.H., eds., Geological implications of impacts and large asteroids and comets on the Earth: Geological Society of America Special Paper 190, p. 243-249

Vonhof, H.B., and Smit, J., 1999, Late Eocene microkrystites and microtektites at Maude Rise (ODP Hole 689B; Southern Ocean) suggest a global ex tension of the $\sim 35.5 \mathrm{Ma}$ Pacific impact ejecta strewn field: Meteoritics and Planetary Science, v. 34, p. 747-756.

Wallace, M.W., Gostin, V.A., and Keays, R.R., 1990, Acraman impact ejecta and host shales: Evidence for low-temperatuure mobilization of iridium and other platinoids: Geology, v. 18, p. 132-135.

Wang, K., 1992, Glassy microspherules (microtektites) from an Upper Devonian Limestone: Science, v. 256, p. 1546-1549.

Weissman, P.R., 1985, Cometary dymanics: Space Science Reviews, v. 41, p. 299-349.

Wetherill, G.W., and Shoemaker, E.M., 1982, Collision of astronomically observable objects with the earth: Geological Society of America Special Paper 190, p. 1-13.

Whitmire, D.P., and Jackson, A.A., 1984, Are periodic mass extinctions driven by a distant solar companion?: Nature, v. 308, p. 713-715.

Whitmire, D.P., and Matese, J.J., 1985, Periodic comet showers and planet X: Nature, v. 313 , p. $36-38$

Williams, G.E., 1986, The Acraman impact structure: Source of ejecta in the late Precambrian shales, South Australia: Science, v. 233, p. 200-203.

Xu, D., Ma, S., Chai, Z., Mao, X., Sun, Y., Zhang, Q., and Yang, Z., 1985, Abundance variation of iridium and trace elements at the Permian/Triassic boundary at Shangsi in China: Nature, v. 314, p. 154-156.

Zachos, J.C., Quinn, T.M., and Salamy, K.A., 1996, High-resolution ( $10^{4}$ years) deep-sea foraminiferal stable isotope records of the Eocene-Oligocene climate transition: Paleoceanography, v. 11, p. 251-256.

Zahnle, K., 1996, Tunguska: Leaving no stone unburned: Nature, v. 383, p. 674-675.

Zhou, L., and Kyte, F.T., 1988, The Permian-Triassic boundary event: A geochemical study of three Chinese sections: Earth and Planetary Science Letters, v. 90 , p. 411-421.

Zhou L., Kyte F.T., and Bohor B.F., 1991, Cretaceous/Tertiary boundary of DSDP Site 596, South Pacific: Geology, v. 19, p. 694-697.

Zolensky, M., Barrett, R., and Browning, L., 1993, Mineralogy and composition of matrix and chondrule rims in carbonaceous chondrites: Geochimica et Cosmochimica Acta, v. 57, p. 3123-3148.

Zoller, W.H., Parrington, J.R., and Phelan-Kotra, J.M., 1983, Iridium enrichment in airborne particles from Kilauea volcano: January 1983: Science, v. 222 , p. $1118-1120$

MANuSCRIPT SUbmitTed December 7, 2000; ACCEPTED By THE SOCIETy MARCH 22, 2001 